\title{
How valuation approach choice affects financial analysts' target price accuracy
}

\author{
Gülcan Erkilet ${ }^{1} \cdot$ Gerrit Janke $^{2} \cdot$ Rainer Kasperzak $^{1}$
}

Accepted: 13 August 2021 / Published online: 21 September 2021

(C) The Author(s) 2021

\begin{abstract}
This paper examines which valuation approaches financial analysts use to value a company and whether the chosen valuation approach affects the target price accuracy. To address these questions, we conduct content analyses of 867 hand-collected analyst reports on German publicly listed companies published between January 2014 and June 2017. We find that sell-side analysts more frequently use the single-period market approach when formulating target prices, followed by the multiperiod income approach, and a mixture of both by combining the results, the socalled hybrid valuation approach. Additionally, we show that 612 of the analyzed analyst reports are based on a holistic valuation methodology instead of a sum of the parts valuation technique. Both univariate and multivariate analyses emphasize that the choice of valuation approach is significantly associated with the accuracy of price targets. Specifically, the income and market approach lead to significantly more accurate target prices compared to the hybrid approach. We also find that the target price accuracy is higher when analysts apply the holistic rather than the sum of the parts valuation approach to determine the fundamental value of the company. Additional results emphasize that target price accuracy improves when analysts use the sum of the parts valuation that bases solely on market or income approaches rather than hybrid approaches. Hence, we contribute to theory and practice by providing evidence on the link between the choice of valuation approach and the analysts' target price accuracy as well as on the performance of certain valuation techniques.
\end{abstract}

Keywords Target prices · Analyst reports · Financial analysts · Valuation methods · Sum of the parts

JEL classification $\mathrm{G} 11 \cdot \mathrm{G} 12 \cdot \mathrm{G} 17 \cdot \mathrm{G} 24$

Rainer Kasperzak

rainer.kasperzak@uni-due.de

Extended author information available on the last page of the article 


\section{Introduction}

This study investigates whether the valuation approach choice of financial analysts is associated with the target price accuracy. Specifically, we investigate whether the application of an income approach, mainly driven by discounted cash flow (DCF) techniques, a multiples-based market approach or a mixture of both (i.e. hybrid approach) affects analysts' ability to forecast prices more accurately. Additionally, this paper analyzes the impact of the sum of the parts (SOTP) valuation on the accuracy of target prices compared to the holistic valuation approach.

It is important to question the link between the choice of valuation approach and the price target that is formulated based on the applied valuation technique. In research, we need a better understanding of analysts' work process, which is commonly referred to as a 'black box' (Bradshaw 2011; Healy and Palepu 2001; Ramnath et al. 2008; Schipper 1991). While it covers analysts' information processing and evaluation activity, forecasting and valuation approach choice, and the subsequent technical valuation of the company (Asquith et al. 2005; Demirakos et al. 2010), the specific mechanics and determinants are not yet fully understood. Extant literature suggests that analysts predominantly use single-period multiple models, followed by multi-period DCF models to determine price targets (e.g., Asquith et al. 2005; Demirakos et al. 2010; Imam et al. 2013). Analysts are also sensitive to segmental disclosures and frequently refer to this information in their reports (Demerens et al. 2017). However, previous research on whether analysts actually value the company by its parts or as stand-alone entity is limited and shows inconsistent results (Chlomou and Demirakos 2020; Demerens et al. 2017; Paarz 2011). Arguably, the list of possible methods and modifications that financial analysts may use in practice is very long (for examples see Imam et al. 2013). For instance, analysts commonly make subjective adjustments to the face value of the company valuation exercise to derive the target price which tend to produce considerably more accurate results (Bonini and Kerl 2014). As Demirakos et al. (2010) note, further research on alternative valuation models and the combined use of alternative models to formulate price targets is needed.

Financial analysts play a major role as information intermediaries on global capital markets (Brown et al. 2015; Cascino et al. 2014). Given that they are equipped with specialist knowledge, they acquire and evaluate valuation-relevant information and communicate the results to the capital market in aggregated form (Asquith et al. 2005; Kelly et al. 2012; Oberdörster 2009). Regarding the input of this work process, analysts use data from traditional financial reporting, other publicly available sources of information and private information through, for example, management contacts (Cascino et al. 2014). In addition to earnings forecasts and stock recommendations (e. g., buy, sell, and hold), a key output is the target price that analysts typically provide in their reports, which are publicly available to private and institutional investors (Grüber 2015; Groysberg et al. 2008). In contrast to earnings estimates and stock recommendations, the formulated price target is an expression of the fundamental value of a company (Demirakos et al. 2010) and therefore provides valuable information to investors 
(Asquith et al. 2005; Brav and Lehavy 2003). Until recently, however, target prices and the upstream valuation process attracted limited attention in research compared to stock recommendations and earnings estimates. In addition, prior studies dealing with the link between valuation method choice and analysts' target price accuracy show inconsistent results. Asquith et al. (2005) fail to provide evidence that price target attainability is associated with the valuation method choice. Demirakos et al. (2010) also do not find significant differences in the target price forecasting performance of DCF models and multiples-except for one model specification indicating a better performance of DCF models than multiples. Gleason et al. (2013) also suggest that the quality of target prices improves significantly when analysts appear to use fundamental valuation techniques rather than simple heuristics. Moreover, the results of Imam et al. (2013) emphasize that price targets are more often met when financial analysts combine accrual based and cash flow models.

As described above, analysts rely on public and private sources of information when choosing a certain valuation approach that they use in their main work process. Thereby, they produce information for capital market participants in order to fulfil their role as information intermediaries. Thus, analysts make informed valuation method choice to determine price targets (Demirakos et al. 2010) that support investors and other market particpants to make informed investment decisions. In this regard, the question of whether certain valuation techniques are better suited to determine the fundamental value of a company is of considerable relevance to the theory of company valuation and of course to all market participants. Therefore, our study mainly addresses three research questions:

1. Does the choice of valuation approach by financial analysts influence the target price accuracy?

2. Do financial analysts use more frequently income, market, or hybrid models to determine price targets, and how do these approaches perform in terms of target price accuracy when comparing among each other?

3. Do financial analysts prefer valuing companies as the sum of its part or by using a holistic approach, and which approach yields more accurate target price estimates?

To address these questions, we analyze the content of 867 analyst reports written by 35 different brokerage houses for 26 German publicly listed companies published between January 2014 and June 2017. We also collect firm and market data from the database Thomson Reuters Eikon. We first classify whether the respective analyst uses the income approach, the market approach or the hybrid approach, which is a combination of the first two methods, when formulating target prices. Then, we categorize, regardless of the first classification, whether the analyst uses the holistic or SOTP valuation approach to estimate the price target. Next, we employ univariate and multivariate analyses to study whether the valuation approach choice is associated with the target price accuracy, and how the performance of the chosen approaches differs. Using probit regressions and 
two-stage least square regressions (2SLS), we additionally examine determinants of both valuation approach choice and target price accuracy. The target price accuracy is defined as the absolute difference between the target price forecast and the stock price at the end of the 12-month forecast horizon, scaled by the stock price at the end of the 12-month forecast horizon.

The content analysis shows that sell-side analysts more frequently use the market approach (39\%) to determine price targets, followed by the income (33\%) and hybrid approaches (28\%). Examining hybrid approaches in detail, we find that 109 of 245 (44\%) hybrid calculation combine DCF techniques with 1 multiple (35 PE multiples, 55 EV/EBIT multiples, 19 other multiples (e.g., EV/Sales or CROCE) and about $53 \%$ (131) combine DCF calculation with 2 or more multiples. Regarding the second classification, only $30 \%$ of analyzed reports are based on the SOTP and $70 \%$ on the holistic valuation approach. Both univariate and multivariate analyses indicate a significant association between the choice of valuation approach and the target price accuracy. While the income and market approach do not significantly differ in the forecasting quality, we provide evidence that both approaches lead to significantly higher target price accuracy than the hybrid valuation approach. We find that analysts are more likely to use income approaches when the valued firm is smaller, less risky and reports fewer segments under IFRS 8. In contrast, analysts are more likely to apply the market approach when the valued firm is larger, riskier, has more growth opportunities, higher leverage and more industry peers in the Stoxx Europe 600 . The decision to value the firm based on hybrid calculations is significantly determined by firms' risk-level, leverage and profitability.

The results also emphasize that the target price accuracy is significantly higher when analysts use the holistic rather than SOTP valuation approach. Analysts are more likely to apply SOTP rather than holistic calculation when the valued firm is larger, riskier, more profitable, and has fewer growth opportunities as well as more reporting segments. When investigating the SOTP valuation framework in detail, we find that the target price accuracy decreases when analysts use the sum of the parts valuation that bases solely on hybrid approaches rather than market or income approaches. Thus, the market and income approaches also dominate the hybrid approach in terms of target price accuracy in the SOTP valuation framework.

This paper contributes to prior research in several ways. First, prior research focuses on certain valuation methods and determine dominant models. In contrast, we use a more holistic but very distinctive framework to identify the applied valuation techniques by considering multi-period income valuation approaches, singleperiod market approaches, and hybrid approaches. The latter one has attracted limited attention in research even if it might dominate in practice. Thus, we follow the recommendation of Demirakos et al. (2010) to additionally investigate the usage and performance of combined models. In this regard, we provide descriptive statistics on how analysts actually combine income and market models when using the hybrid approach and provide empirical evidence on how hybrid calculations perform in predicting target prices. Second, we shed light on whether analysts prefer to use SOTP or holistic approaches to value a company. Like hybrid approaches, the SOTP valuation has been mostly ignored by researchers and academics, although it is widely used in practice (Chlomou and Demirakos 2020). Third, we analyze 
the performance of each approach in terms of target price accuracy and investigate whether certain approaches are better suited to estimate price targets. In this respect, we conduct a comprehensive investigation that includes content analyses as well as univariate and multivariate analyses. This study also gives insights into the determinants of analysts' valuation approach choice and target price accuracy.

The remainder of this paper is structured as follows. Section 2 reviews prior literature and Sect. 3 develops the main hypotheses of this study. In Sect. 4, we describe the research methodology. Section 5 discusses the empirical results. Section 6 concludes.

\section{Literature review}

This paper contributes to prior studies dealing with the valuation method choice of financial analysts and/or the target price accuracy. Extant literature suggests a trend in the frequency of valuation methods financial analysts employ to value a company (e.g., Asquith et al. 2005; Barker 1999; Block 1999; Bradshaw 2002; Demirakos et al. 2004). Analysts primarily use single-period models, such as multiples, followed by multi-period DCF valuation approaches; other methods-e.g. the real option methods, residual profit methods or dividend-discounting models - only play a secondary role. Recent research by Imam et al. (2013) and Brown et al. (2015) observe the same application patterns regarding analysts' valuation methods. However, prior studies focus on multiples or DCF models and neglect that analysts might combine both valuation approaches to determine the fundamental value of a company, which is reflected by the target price analysts specify in their equity research reports (Demirakos et al. 2010).

While prior research extensively studied financial analysts' earnings estimates and stock recommendations (e.g., Healy and Palepu 2001; Kothari 2001; Rahmath et al. 2008), research on target prices is comparably scarce. It is a major output of analysts' work process that mainly involves the assessment of firm specific cash flows and risk levels, industry prospects, and macroeconomic factors (Asquith et al. 2005). Target prices provide valuable information to investors (Asquith et al. 2005; Brav and Lehavy 2003) and reflect analyst's view regarding the fundamental value of the underlying security. The target price accuracy reflects both analysts' forecasting skills and information environment (Bilinski et al. 2013) as well as other determinants that have been investigated by some researchers. In this context, prior studies find that the target price accuracy decreases with the expected return implied by the target price, the market value/book value ratio, and the volatility of the respective share (Bilinski et al. 2013; Bonini et al. 2010; Kerl 2011). Dechow and You (2019) document that analysts tend to derive optimistically biased target prices for riskier stocks (e.g. measured by volatility or beta) whereas the degree of optimism outweighs the expected return implied by the stock's risk profile. Moreover, Kerl (2011) finds that the target price accuracy increases with the size of the company to be valued as well as the information depth of the analyst report. Bilinski et al. (2013) document that the target price accuracy increases with the experience of a financial analyst, the number of companies that are regularly analyzed, and the quality 
of disclosed accounting information. In addition, Bonini et al. (2010) show that the target price error increases for those companies for which financial analysts expect a loss according to the consensus EPS estimate.

The question how the valuation approach choice of analysts is related to the target price accuracy remains broadly unaddressed. To the best of our knowledge, only four studies exist that directly examine this association (Asquith et al. 2005; Demirakos et al. 2010; Gleason et al. 2013; Imam et al. 2013). Using a data set of 1126 analyst reports published between 1997 and 1999 for US-firms, Asquith et al. (2005) show that target prices provide valuable information to capital markets. Specifically, they find that market reaction to price target revisions is strong even if earnings revisions and stock recommendations are available to capital market participants. However, they fail to provide evidence for a correlation between valuation method used by a financial analyst and the probability of achieving a price target. Hereby they observe that analysts more frequently use multiples than cash flow-oriented valuation approaches. Demirakos et al. (2010) investigate 490 analyst reports for UKfirms published between July 2002 and June 2004. They compare the frequency with which analysts employ a DCF model or price-to-earnings (PE) multiple to determine the target price. In addition, they analyze the determinants of valuation method choice and compare the target price accuracy of DCF and PE models. The results indicate that analysts use DCF model significantly more frequently than PE models if the firm is small, loss making, considered high risk, has unstable sales growth, and has a limited number of industry peers. With regard to the performance of each valuation technique in forecasting target prices, they suggest that both methods do not significantly differ in performance. Only one model specification indicates that DCF models perform better than multiples. Imam et al. (2013) analyze the content of 62 equity research reports on 45 firms of the Dow Jones Euro Stoxx 50 Index published over the period January 2005 to January 2007. They show that analysts predominantly use earnings multiples, followed by the DCF model, to value European firms. Additionally, Imam et al. (2013) find that target prices are met more often in the 12-month forecast horizon if the firm value is calculated by combining cash flow and accrual based models. In contrast to these studies, Gleason et al. (2013) do not conduct content analyses of analyst reports. Rather, they use a data set comprising 45,693 target prices published in the period 1997-2003 for US-firms in order to draw conclusions about the valuation methods presumably used to calculate the target prices. The authors then examine whether certain valuation methods lead to more accurate target prices. Gleason et al. (2013) show that the quality of target prices improves significantly when analysts appear to use fundamental valuation techniques (e.g., the residual income model) rather than simple heuristics (e.g., PEG ratio). This improvement is more pronounced for analysts who provide more accurate earnings estimates, especially as these are used as input in both valuation approaches.

However, analysts also decide whether they use, for example, a DCF model or a PE multiple to value the company as a whole or select one of the methods only for certain units of the company and add up the partial results at the end (i.e., SOTP). Thus, it is also worth investigating whether analysts apply a holistic or a SOTP approach to determine the fundamental value of the company, and how 
the performance of these approaches differs in terms of target price accuracy. As Chlomou and Demirakos (2020) already note, the SOTP valuation framework has been mostly ignored by researchers and academics, although it represents a popular approach among sophisticated practitioners. In particular, the accuracy of company valuations derived from SOTP compared to a holistic valuation has not yet been sufficiently investigated. Chlomou and Demirakos (2020) analyze the content of 265 equity research reports for 140 UK-based firms to investigate how analysts implement the SOTP valuation approach and how it differs from holistic valuations in target price accuracy. They note that in about $70 \%$ or 185 of the analyzed reports the analysts use the SOTP approach as preferred model rather than a DCF calculation as stand-alone model. Using univariate analyses, they fail to provide evidence that the SOTP valuation significantly outperform the DCF calculation, when the latter is used to value the company as a whole. However, Chlomou and Demirakos (2020) also suggest that in a sample of equity research reports written by 4 and 5 star analysts, which is based on Thomson Reuters Eikon methodology of analysts' rankings, the popularity of SOTP increases to $26.46 \%$. Paarz (2011) investigates 2779 analyst reports of 249 German publicly listed firms from 1998 to 2007 and contrary note that only about $26 \%$ of the target prices base on a SOTP calculation. However, he also does not find a statistically significant association between the SOTP approach and the accuracy of target price forecasts. In contrast, You (2014) shows that conglomerates with business units operating in industries with different valuation multiples face incentives to shift profits to highly valued segments. Ceteris paribus, SOTP valuation models that do not account for this earnings management behavior generate systematically overpriced valuation results. However, Green et al. (2016) remark that some analysts even genuinely make theory-related mistakes and/or questionable economic judgements in order to present the company in a particular way and tweak valuation accordingly.

\section{Hypotheses development}

Generally, a company can be valued either by discounting future economic benefits (mainly cash flows, dividends or abnormal earnings, the income approach) or using a relative valuation approach, i.e., market-based valuation with multiples (market approach). In practice, it is also common that financial analysts use a mixture of valuation models and derive the target price by weighting the calculated results (hybrid approach). Nevertheless, prior studies dealing with the frequency at which analysts apply specific valuation approaches when formulating target prices suggest a dominance of multiples as single-period valuation models (Demirakos et al. 2004; Imam et al. 2013). Empirical studies also arrive at different results regarding the quality of valuations using multiples methods as opposed to present value-based valuation calculations. Hence, there is no consistent evidence on the performance of the valuation methods examined (see chapter 2).

While market based multiples infer the market value directly through a comparison of ratios with other companies already valued by the market, the cost of capital, which is typically derived directly from the capital market, is the primarily market 
reference value reflected in income approach calculations (Damodaran 2012). Especially the DCF as a multi-period valuation method is typically considered to have methodological superiority over multiple-based methods, due to the reference to the widely accepted capital market theory. Relative valuation approaches are therefore frequently considered as naïve valuation heuristics or 'rules of thumb' (Gleason et al. 2013; Imam et al. 2008). However, any valuation model, particularly a multiperiod DCF-driven calculation, are prone to opportunistic application and manipulation (Imam et al. 2013). Even if the published target price is based on a DCF calculation, the market sentiment and current multiples represent a strong benchmark for the input used in DCF models. In this regard, the DCF-driven target price does not reflect the unbiased fundamental value but is strongly influenced by the market view about the respective company. This is also indicated by the fact that multiples are commonly published in the analyst reports examined, even if the target price was determined exclusively using the income approach.

In practice, financial analysts often use the income and market approach in combination by weighting the results achieved (Demirakos et al. 2010). This can be interpreted as an attempt to objectify the strongly subjective income approach with market expectations. However, it is questionable whether a practical mixture of both approaches leads to an accurate estimate of a firm's fundamental value, particularly because the hybrid approach is not clearly expressed in theory. ${ }^{1}$ Specific rules and guidelines for the application of a hybrid model are missing and analysts rely on their own judgement when applying it and weighting the results obtained by different valuation techniques. In addition, research on the hybrid approach is limited and there is therefore no clear theoretical underpinning or empirical evidence on its performance. Also with regard to the discussions above, it is debatable whether a mixture of the two basic valuation techniques, i.e., fundamental and relative valuation methods, lead to superior/inferior target price estimates.

In view of these considerations, we derive the following non-directional null hypotheses:

H1a: There is no association between the choice of the valuation approach and analysts' target price accuracy.

H1b: The income and market valuation approaches do not lead to more/less accurate target price forecasts than hybrid valuation approaches.

Financial analysts study companies either as a holistic entity or value the individual divisions, business units or segments separately, and then combine these partial results to determine the value of the company as a whole (Damodaran 2012; Koller et al. 2015). This approach, known as SOTP valuation, is not only particularly suitable for diversified companies with different profitability, growth perspectives and

\footnotetext{
1 This is particularly true if analysts do not explicitly disclose the weightings they apply to the different valuation approaches used when deriving the target price. Note that one limitation of our empirical study is that we do not identify the instances where financial analysts combine income approaches with several market approaches for our multivariate analyses. We only provide descriptive statistics on the combination of income and market approaches in the hybrid valuation framework (Sect. 4.2).
} 
risk profiles per segment but is also recommended for the valuation of the business units of large companies operating in a single sector (Koller et al. 2015). Based on the assumption that SOTP offers a deeper insight into the opportunities, risk structure and the process of value creation, it is assumed that the SOTP approach provides better valuation results than the holistic valuation of the company (Damodaran 2012; Koller et al. 2015). The very few empirical studies carried out to date on target price estimates by financial analysts-depending on the specific design of the statistical analyses-have produced inconsistent results in this respect (Chlomou and Demirakos 2020; Paarz 2011). The hypothesis to be tested is as follows:

H2: The SOTP approach leads to more accurate target price estimates than the holistic valuation of companies.

\section{Data description and research design}

\subsection{Classification of valuation approaches}

The valuation methods used by financial analysts can be derived either by analyzing the information provided in equity research reports or by using a statistical model for approximation (Gleason et al. 2013). Since the large amount of information communicated via analyst reports describes, inter alia, the methods used and the obtained results of applying these methods, research reports are particularly well suited for content analysis (Imam et al. 2013). Thus, we perform a comprehensive content analysis of analyst reports to identify the valuation approach used by the financial analyst to estimate the respective target price.

However, the classification of the valuation approach used in each case is not straightforward, especially if financial analysts are using several different approaches simultaneously. Demirakos et al. (2010) and Imam et al. (2013), for example, focus on the dominant valuation method without elaborating on the characteristics the dominance criterion is based on. Similarly, if two valuation methods are used concurrently with a weighting attached, it is highly subjective to determine which cutoff weighting is to be considered dominant. The more valuation approaches are used simultaneously, the more difficult it becomes to determine a single dominant valuation model. Additionally, when the target price is derived from several methods and only the dominant approach is considered for further analyses, the classification then might bias the empirical results. Consequently, we do not follow the dominance criterion suggested by prior researchers to classify the observations into the analyzed valuation categories. Instead, we apply the following three-part categorization (classification I):

- Market approach: If the target price is determined exclusively by market-based ratios, i. e. multiples, that perform a peer group comparison. In this context, the particular type of used multiple is not relevant. For example, we consider earnings multiples, book value multiples, revenue multiples and sector-specific multiples. 
- Income approach: If the target price is determined exclusively by cash flowbased, dividend-based, or earnings based valuation methods. This also includes discounted cash flow (DCF), dividend discount models (DDM) and residual income models (RIM).

- Hybrid approach: If the target price is determined by any combination (independent of the weighting) of income and market approach models. This procedure eliminates distorting effects due to the definition of subjective limits regarding the dominance of a particular valuation technique.

Moreover, as this study also analyzes the influence of a sum of the parts valuation on the accuracy of target prices, we classify-independent of the previous categorization-the used valuation approach as SOTP approach if the analyst values the individual parts of the company separately and then sums the results up to get to the fundamental value of the company (classification II). In some cases, the analyst uses a SOTP approach alongside the other valuation techniques within a hybrid approach to value the company by weighting the results of several specifications. If this is the case, we do not consider the valuation approach as SOTP to differentiate the analyzed approaches precisely. ${ }^{2}$ In contrast, if the analyst values the company as a whole instead of a sum of its part, we classify the valuation approach as a holistic approach.

\subsection{Data collection and sample selection}

We focus on the stock index DAX, which consists of the 30 largest German publicly listed companies, for at least three reasons. First, country-specific cultural factors and the level of enforcement of accounting standards might influence how capital market participants perceive and process accounting information (Bilinski et al. 2013; Christensen et al. 2013; Wehrfritz 2012). Therefore, focusing on one country aims to prevent any bias resulting from diverging cultural, institutional, and/or regulatory factors. Second, the German DAX30 index covers companies that represent a large number of industries without showing excessive accumulation in certain sectors. ${ }^{3}$ This avoids the occurrence of biases by dominant industries. Third, the DAX is a blue chip stock market index and the included firms have to fulfil the very high transparency requirements of the Frankfurt Stock Exchange. Besides providing a regular flow of information and a high level of accounting quality, for example, these firms mandatorily publish group management reports, ${ }^{4}$ including forwardlooking information that supports analysts in determining, verifying, and revising

\footnotetext{
2 To examine whether this methodological choice has any effect on the results of our study, we (1) vary the classification by considering these observations as SOTP and (2) drop these observations from the control group. Untabulated results of both modifications emphasize that our main results are robust.

3 Imam et al. (2013), for example, examine 62 analyst reports, of which 22 refer to companies in the financial services sector. Accordingly, their results might be highly biased by specific valuation procedures that analysts apply for firms of this certain sector.

4 The group management report has to be prepared according to $\S 315$ HGB (Handelsgesetzbuch; German Commercial Code (German-GAAP)) and German Accounting Standard No. 20 (GAS 20).
} 


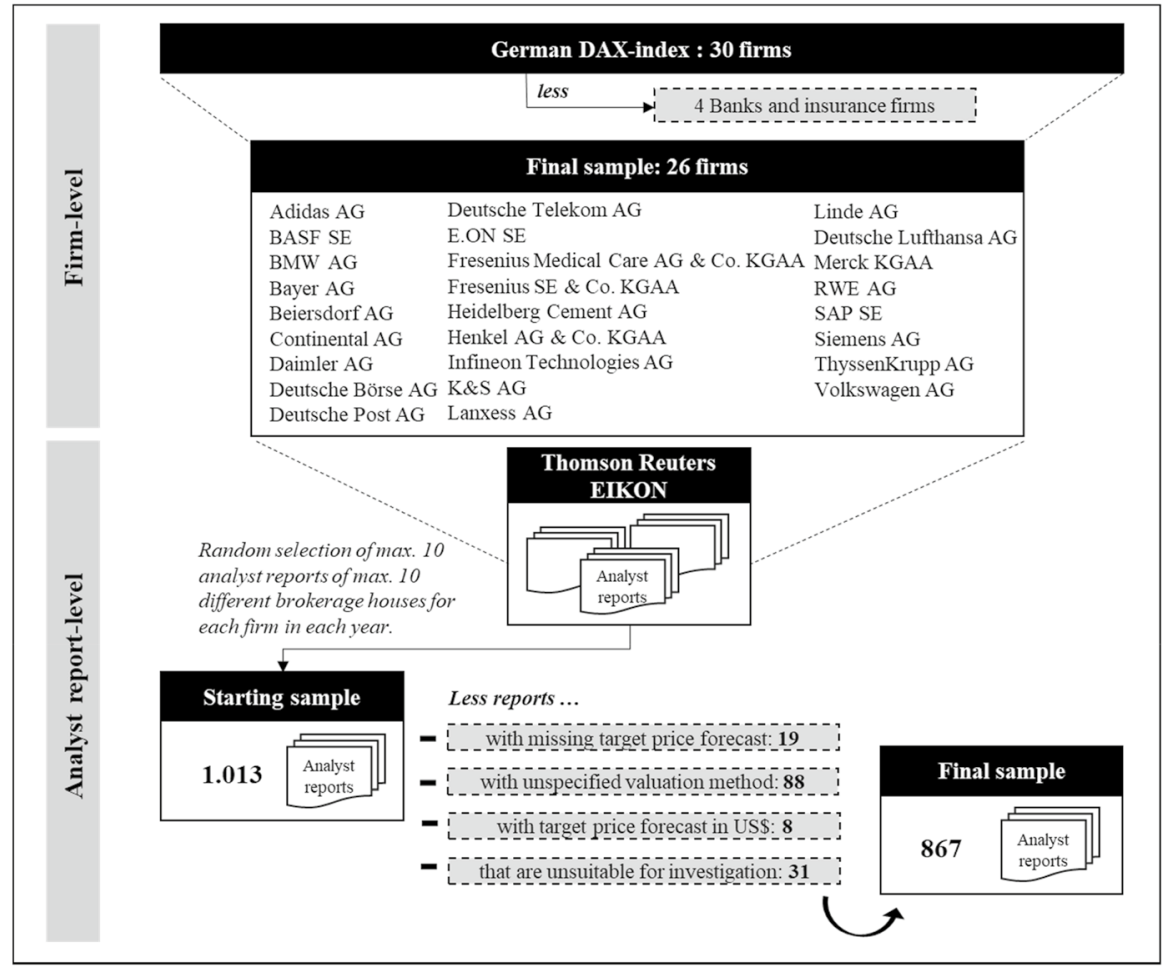

Notes: This figure visualizes the sample selection process both at firm and analyst report-level. The sample selection yields a final sample consisting of 26 firms and 867 analyst reports.

Fig. 1 Sample selection process

their forecasts. Thus, analysts are able to make informed valuation method choice (Demirakos et al. 2010), which is an important assumption to study the performance of different valuation techniques with regard to the target price accuracy.

Figure 1 illustrates the data collection and sample selection process. We exclude four firms from the financial industry (banks and insurance companies), as they differ significantly from other firms (e.g., regarding accounting characteristics or regulatory issues) and analyst use specific valuation models for this industry (Grüber 2015; Sengupta 1998). The final sample consists of 26 DAX-firms, for which we obtain firm and market data from the Thomson Reuters Eikon database.

To investigate the research questions, we download equity research reports from the Thomson Reuters Eikon database for the identified firms published between January 2014 and June 2017. The Thomson Reuters Eikon database covers 26,421 analyst reports for the DAX firms during the sample period of this study (thereof 12,815 with more than 10 pages length) - in 2014 a total of 7630 (3586) analyst reports, 2015 in total 7596 (3652) reports, in 2016 a total of 7582 (3664) reports, and until June 2017 in total 3613 (1913) reports. Typically, there are several publications per brokerage house for a firm within a calendar year, as financial analysts adjust their 
forecasts if the firm develops differently than expected or new value relevant information becomes available. Consequently, we randomly select per firm and per year up to 10 analyst reports from 10 different brokerage houses (depending on availability or number of different brokerage houses publishing reports for the respective firm). We only consider reports with a minimum length of ten pages to ensure that the reports provide detailed information on the applied valuation approach. ${ }^{5}$ This yields 1013 equity research reports that we read entirely and conduct careful content analysis on to identify the underlying valuation technique for the target price estimate. We could not consider all of these reports for further analyses and exclude 19 reports with missing target price forecasts, 88 reports with unspecified valuation methods, 8 reports with target price forecasts in US\$ instead of $€$, and 31 reports that are unsuitable for further investigation, e. g. foreign language reports or industry benchmark reports. The final sample consists of 876 equity research reports written by 35 different brokerage houses for 26 firms from 2014 to 2017. Panel A of Table 1 presents the sample distribution by firm and year. In Panel B of Table 1, we show the sample distribution by brokerage house and year.

The content analysis shows that sell-side analysts more frequently use the market approach (39\%; 340 obs.) when formulating target prices; followed by the income (33\%; 282 obs.) and hybrid approaches (28\%; 245 obs.). The identified frequencies are in general consistent with prior research by Asquith et al. (2005), Demirakos et al. (2010), and Imam et al. (2013), who find that analysts predominantly use multiples (e.g., PE models) compared to cash flow-oriented valuation techniques (e.g., DCF). However, we additionally show that financial analysts also frequently use the hybrid approach in practice. Examining hybrid approaches in detail (Panel D of Table 1), we find that 109 of 245 (44\%) hybrid calculation combine DCF techniques with 1 multiple-35 with PE multiples, 55 with EV/EBIT multiples, and 19 with other multiples (e.g., EV/Sales or CROCE). The majority of analyzed hybrid approaches in our sample (131 calculations; 53\%) combine DCF calculation with 2 or more multiples. Other 5 combinations use, for example, DDM and RIM models in combination to multiples. Using the second classification strategy as describes in Sect. 4.1, we show that 612 or $70 \%$ of the analyzed analyst reports are based on a holistic valuation methodology instead of a SOTP technique. This is contrary to the main results of Chlomou and Demirakos (2020), but it is in line with the claim of Chlomou and Demirakos (2020) that in a sample of equity research reports written by 4- and 5-star analysts, which base on Thomson Reuters Eikon methodology of analysts' rankings, the popularity of SOTP rises to $26.46 \%$. This result is also consistent with the result of Paarz (2011), who find a similar application pattern for German publicly listed firms from 1998 to 2007.

\footnotetext{
5 Very short analyst reports usually do not contain separate sections with a dedicated company valuation and a description of the underlying valuation methods. Instead, the impact of specific events on earnings estimates for example is discussed, see Demirakos et al. (2004). Similarly to our approach, other authors also exclusively consider analyst reports with a certain minimum length. For example, Demirakos et al. (2004) and Imam et al. (2013) only include analyst reports with at least fifteen pages in their study. Imam et al. (2013) focus on equity research reports that contain at least 6000 words (equivalent to approx. $15-17$ pages).
} 
Table 1 Sample distribution

Panel A: Sample distribution by firm and year

\begin{tabular}{|c|c|c|c|c|c|}
\hline Firm & 2014 & 2015 & 2016 & 2017 & Total \\
\hline Adidas & 9 & 10 & 9 & 8 & 36 \\
\hline BASF & 7 & 9 & 9 & 7 & 32 \\
\hline Bayer & 9 & 9 & 7 & 9 & 34 \\
\hline Beiersdorf & 7 & 9 & 8 & 8 & 32 \\
\hline BMW & 10 & 9 & 6 & 7 & 32 \\
\hline Continental & 9 & 8 & 8 & 8 & 33 \\
\hline Daimler & 10 & 8 & 9 & 9 & 36 \\
\hline Deutsche Börse & 8 & 7 & 7 & 7 & 29 \\
\hline Deutsche Post & 8 & 9 & 9 & 9 & 35 \\
\hline Deutsche Telekom & 10 & 9 & 9 & 8 & 36 \\
\hline E.ON & 10 & 9 & 7 & 9 & 35 \\
\hline Fresenius & 8 & 10 & 9 & 7 & 34 \\
\hline Fresenius Medical Care & 8 & 9 & 6 & 7 & 30 \\
\hline Heidelberg Cement & 8 & 9 & 6 & 9 & 32 \\
\hline Henkel & 8 & 10 & 8 & 7 & 33 \\
\hline Infineon & 10 & 10 & 10 & 9 & 39 \\
\hline $\mathrm{K}+\mathrm{S}$ & 10 & 7 & 7 & 7 & 31 \\
\hline Lanxess & 9 & 8 & 6 & 7 & 30 \\
\hline Linde & 10 & 9 & 8 & 6 & 33 \\
\hline Lufthansa & 10 & 8 & 9 & 9 & 36 \\
\hline Merck & 7 & 8 & 9 & 8 & 32 \\
\hline RWE & 10 & 10 & 9 & 9 & 38 \\
\hline SAP & 9 & 9 & 6 & 7 & 31 \\
\hline Siemens & 7 & 8 & 8 & 7 & 30 \\
\hline ThyssenKrupp & 6 & 10 & 9 & 8 & 33 \\
\hline Volkswagen & 10 & 9 & 8 & 8 & 35 \\
\hline Total & 227 & 230 & 206 & 204 & 867 \\
\hline
\end{tabular}

Panel B: Sample distribution by brokerage house and year

\begin{tabular}{|c|c|c|c|c|c|}
\hline Brokerage house & 2014 & 2015 & 2016 & 2017 & Total \\
\hline ABN AMRO Bank & 1 & 1 & & & 2 \\
\hline Baader Bank AG & 8 & 14 & & & 22 \\
\hline Barclays Bank PLC & 16 & 20 & 22 & 18 & 76 \\
\hline BMO Investment Banking Group & & & & 1 & 1 \\
\hline BTIG LLC & 1 & 1 & & & 2 \\
\hline Commerzbank AG & 12 & 10 & 10 & 8 & 40 \\
\hline Cowen \& Company LLC & & & 1 & 1 & 2 \\
\hline Credit Suisse Group AG & 18 & 19 & 8 & 12 & 57 \\
\hline Davy Group & & & & 1 & 1 \\
\hline Deutsche Bank AG & 17 & 23 & 24 & 21 & 85 \\
\hline Equinet Bank AG & 11 & 7 & 5 & 4 & 27 \\
\hline
\end{tabular}


Table 1 (continued)

Panel B: Sample distribution by brokerage house and year

\begin{tabular}{|c|c|c|c|c|c|}
\hline Brokerage house & 2014 & 2015 & 2016 & 2017 & Total \\
\hline EQUITA SIM SpA & 3 & 3 & 5 & 1 & 12 \\
\hline Evercore Group LLC & & 1 & 1 & 1 & 3 \\
\hline Goodbody Stockbrokers & & 1 & & & 1 \\
\hline Grupo Santander & 3 & & & & 3 \\
\hline Hauck \& Aufhäuser Privatbankiers KGaA & 1 & 1 & 1 & 2 & 5 \\
\hline HSBC Bank PLC & 14 & 14 & 15 & 17 & 60 \\
\hline Investec Bank PLC & & 1 & & & 1 \\
\hline J.P. Morgan Chase \& Co & 20 & 17 & 18 & 21 & 76 \\
\hline Jefferies Group LLC & 6 & 13 & 12 & 11 & 42 \\
\hline Kepler Cheuvreux & 11 & 3 & 6 & 5 & 25 \\
\hline Liberum Capital Limited & 5 & 5 & 4 & 2 & 16 \\
\hline M.M.Warburg \& CO & 12 & 11 & 6 & 11 & 40 \\
\hline Macquarie Group & 4 & 4 & 8 & 5 & 21 \\
\hline MainFirst Bank AG & & & 5 & 4 & 9 \\
\hline Morgan Stanley \& Co. International PLC & 17 & 21 & 15 & 15 & 68 \\
\hline Natixis & 1 & & 2 & & 3 \\
\hline Oddo Seydler Bank AG & & 2 & & & 2 \\
\hline Raymond James Financial Inc & 1 & 1 & 2 & & 4 \\
\hline RBC Royal Bank of Canada & 8 & 7 & 10 & 9 & 34 \\
\hline Redburn (Europe) Limited & & 1 & & 2 & 3 \\
\hline Sadif-Marques Mendes \& Associados Lda & 1 & 1 & & & 2 \\
\hline Societe Generale Group & 13 & 14 & 11 & 16 & 54 \\
\hline Steubing AG & 1 & 1 & 1 & & 3 \\
\hline UBS Limited & 22 & 13 & 14 & 16 & 65 \\
\hline Total & 227 & 230 & 206 & 204 & 867 \\
\hline
\end{tabular}

Panel C: Sample distribution by firm and used valuation approach

\begin{tabular}{|c|c|c|c|c|c|c|c|}
\hline \multirow[t]{2}{*}{ Firm } & \multicolumn{4}{|c|}{ Classification I } & \multicolumn{3}{|c|}{ Classification II } \\
\hline & Income & Market & Hybrid & Total & SOTP & Holistic & Tota \\
\hline Adidas & 19 & 14 & 3 & 36 & 3 & 33 & 36 \\
\hline BASF & 11 & 5 & 16 & 32 & 5 & 23 & 32 \\
\hline Bayer & 10 & 13 & 11 & 34 & 8 & 26 & 34 \\
\hline Beiersdorf & 17 & 6 & 9 & 32 & & 32 & 32 \\
\hline BMW & 2 & 30 & & 32 & 10 & 22 & 32 \\
\hline Continental & 6 & 22 & 5 & 33 & 12 & 21 & 33 \\
\hline Daimler & 2 & 31 & 3 & 36 & 24 & 12 & 36 \\
\hline Deutsche Börse & 12 & 13 & 4 & 29 & 2 & 27 & 29 \\
\hline Deutsche Post & 13 & 4 & 18 & 35 & 23 & 12 & 35 \\
\hline Deutsche Telekom & 21 & 6 & 9 & 36 & 28 & 8 & 36 \\
\hline E.ON & 12 & 2 & 21 & 35 & 24 & 11 & 35 \\
\hline Fresenius & 15 & 6 & 13 & 34 & 10 & 24 & 34 \\
\hline
\end{tabular}


Table 1 (continued)

Panel C: Sample distribution by firm and used valuation approach

\begin{tabular}{|c|c|c|c|c|c|c|c|}
\hline \multirow[t]{2}{*}{ Firm } & \multicolumn{4}{|c|}{ Classification I } & \multicolumn{3}{|c|}{ Classification II } \\
\hline & Income & Market & Hybrid & Total & SOTP & Holistic & Total \\
\hline Fresenius Medical Care & 16 & 5 & 9 & 30 & & 30 & 30 \\
\hline Heidelberg Cement & 13 & 16 & 3 & 32 & & 32 & 32 \\
\hline Henkel & 18 & 9 & 6 & 33 & 6 & 27 & 33 \\
\hline Infineon & 11 & 21 & 7 & 39 & 2 & 37 & 39 \\
\hline $\mathrm{K}+\mathrm{S}$ & 14 & 2 & 15 & 31 & 4 & 27 & 31 \\
\hline Lanxess & 14 & 2 & 14 & 30 & 5 & 25 & 30 \\
\hline Linde & 12 & 8 & 13 & 33 & & 33 & 33 \\
\hline Lufthansa & 8 & 23 & 5 & 36 & 5 & 31 & 36 \\
\hline Merck & 7 & 15 & 10 & 32 & 7 & 25 & 32 \\
\hline RWE & 10 & & 28 & 38 & 26 & 12 & 38 \\
\hline SAP & 12 & 13 & 6 & 31 & 1 & 30 & 31 \\
\hline Siemens & & 22 & 8 & 30 & 10 & 20 & 30 \\
\hline ThyssenKrupp & 2 & 26 & 5 & 33 & 23 & 10 & 33 \\
\hline Volkswagen & 5 & 26 & 4 & 35 & 17 & 18 & 35 \\
\hline Total & 282 & 340 & 245 & 867 & 255 & 612 & 867 \\
\hline \multicolumn{8}{|c|}{ Panel D: Details on hybrid approach } \\
\hline \multicolumn{4}{|l|}{ Total hybrid approach } & 245 & & & \\
\hline \multicolumn{4}{|l|}{ Thereof: } & $\mathrm{n}$ & $\%$ & $\mathrm{n}$ & $\%$ \\
\hline \multicolumn{4}{|c|}{ DCF combined with 1 multiple } & 109 & $44 \%$ & & \\
\hline \multicolumn{4}{|c|}{ Thereof with PE multiple } & & & 35 & $32 \%$ \\
\hline \multicolumn{4}{|c|}{ Thereof with EV/EBIT (or EV/EBITDA; EV/EBITDAR) } & & & 55 & $50 \%$ \\
\hline \multicolumn{4}{|c|}{ Thereof with other multiples (e.g., EV/Sales; CROCE) } & & & 19 & $17 \%$ \\
\hline \multicolumn{4}{|c|}{ DCF combined with 2 or more multiples } & 131 & $53 \%$ & & \\
\hline \multicolumn{4}{|c|}{ Other combinations (e.g., DDM, RIM) } & 5 & $2 \%$ & & \\
\hline
\end{tabular}

This table presents the sample distribution. Panel A presents the sample distribution by firm and year. Panel B shows the brokerage houses by year. Panel C reports the sample by classification into income, market, and hybrid valuation approach as well as into sum of the parts and holistic valuation approach. Panel D provides details on the hybrid approach by analyzing how analysts have actually combined market and income approaches

Panel $\mathrm{C}$ of Table 1 reports the sample distribution by company and used valuation approach.

\subsection{Measure of target price accuracy}

Extant literature suggests various metrics to measure the target price accuracy. One option is to use accuracy metrics determining the price target attainability to estimate how accurate the forecast is (Gleason et al. 2013). Then, the target price is defined as attained or exceeded when some assumptions are met. For example, 
Asquith et al. (2005) and Demirakos et al. (2010) consider a target price to be accurate if firms' stock price meets or exceeds the estimated target price at any time during the 12-month forecast horizon. However, such metrics are criticized since they conclude that a target price forecast is accurate without considering the deviation (under-/overachievement) from the actual share price, i. e. the forecast error. The more the target price deviates from the share price, the less accurate should the forecast by financial analysts be (Kerl 2011). From investors' perspective, this methodology appears to be an incomplete performance measurement since the target price attainability is likely to be inversely related to analysts' optimism (Gleason et al. 2013). Hence, the other option to judge the quality of analysts' target price estimates is to use measures that consider the level of positive and negative deviation from share prices and, therefore, to calculate the forecast error (Kerl 2011).

To address our research question, we use a measure of target price accuracy that reflects the percentage amount of the target price error (Eq. 1).

$$
\mathrm{TPE}_{i j t}=\left|\frac{\mathrm{TP}_{i j t}-P_{12}}{P_{12}}\right| .
$$

The target price error is calculated as the absolute difference between the target price forecast and the stock price at the end of the 12-month forecast horizon, scaled by the stock price at the end of the 12-month forecast horizon. The subscript $i$ refers to a brokerage house, $j$ refers to a firm and $t$ refers to a year. Within robustness tests, we modify the measure and use three other specifications, as share prices might be more sensitive due to confounding events at the end of the 12-month horizon. First, we scale the target price error by the stock price three days before the end of the 12-month forecast horizon (TPE_2). Second, we compute the forecast error as the absolute difference between target price forecast and the mean of the share price 7D, $14 \mathrm{D}, 21 \mathrm{D}$, and 28D before the end of the 12-month forecast horizon, scaled by the share price 3 days before the end of the 12-month forecast horizon (TPE_3). Third, to mitigate biases that may arise from the high share price volatility, we adjust the target price error (TPE_adj) and scale it by the share price volatility (VOLAT, as defined in Table 2) (Kerl 2011).

\subsection{Regression model}

To test our hypotheses, we estimate the following multivariate ordinary least square (OLS) regression model with robust standard errors:

$$
\begin{aligned}
\text { TPE }_{i j t} & =\beta_{0}+\beta_{1} \text { VALUATION }_{i j t}+\beta_{2} \text { PTB }_{j t}+\beta_{3} \text { VOLAT }_{j t}+\beta_{4} \text { FOLLOW }_{j t}+\beta_{5} \text { GROWTH }_{j t} \\
& +\beta_{6} \text { BOLDNESS }_{j t}+\beta_{7} \text { ROA }_{j t}+\beta_{8} L E V_{j t}+\beta_{9} \text { PEERS }_{j t}+\beta_{10} \text { EPS_Acc }_{j t} \\
& \sum \gamma_{i} \text { BROKER }_{i}+\sum \delta_{t} \text { YEAR }_{t}+\varepsilon_{j t}
\end{aligned}
$$

The subscript $i$ refers to a brokerage house, $j$ refers to a firm and $t$ refers to a year. The variable of interest is $V A L U A T I O N_{i j t}$ and stands for the used valuation approaches. With regard to $H I a$ and $H 1 b$ it refers to the dummy variables INCOME, 
Table 2 Definition of variables

\begin{tabular}{|c|c|}
\hline Variable & Definition \\
\hline \multicolumn{2}{|c|}{ Dependent variables } \\
\hline$T P E$ & $\begin{array}{l}\text { Target price error, computed as absolute difference between the target price } \\
\text { forecast and the stock price at the end of the } 12 \text {-month forecast horizon, scaled } \\
\text { by the stock price at the end of the } 12 \text {-month forecast horizon }\end{array}$ \\
\hline naïve_TPE & $\begin{array}{l}\text { Naïve target price error, computed as absolute difference between the naïve } \\
\text { target price forecast and the stock price at the end of the } 12 \text {-month forecast } \\
\text { horizon, scaled by the stock price at the end of the } 12 \text {-month forecast horizon. } \\
\text { The naïve forecast represents the extrapolation of past share prices into the } \\
\text { future prices and is calculated as the share price at the forecast issue date, } \\
\text { multiplied by } 1 \text { plus the return achieved over the last } 365 \text { calendar days before } \\
\text { the forecast issue date }\end{array}$ \\
\hline$T P E \_2$ & $\begin{array}{l}\text { Target price error, computed as absolute difference between the target price } \\
\text { forecast and the stock price at the end of the } 12 \text {-month forecast horizon, scaled } \\
\text { by the stock price } 3 \text { days before the end of the } 12 \text {-month forecast horizon }\end{array}$ \\
\hline$T P E \_3$ & $\begin{array}{l}\text { Target price error, computed as the absolute difference between target price } \\
\text { forecast and the mean of the share price } 7 \mathrm{D}, 14 \mathrm{D}, 21 \mathrm{D} \text {, and } 28 \mathrm{D} \text { before the end } \\
\text { of the } 12 \text {-month forecast horizon, scaled by the share price } 3 \text { days before the } \\
\text { end of the } 12 \text {-month forecast horizon }\end{array}$ \\
\hline TPE_adj & $\begin{array}{l}\text { Target price error, computed as absolute difference between the target price fore- } \\
\text { cast and the stock price at the end of the } 12 \text {-month forecast horizon, scaled by } \\
\text { the stock price at the end of the } 12 \text {-month forecast horizon, and risk adjusted } \\
\text { by the variable VOLAT }\end{array}$ \\
\hline \multicolumn{2}{|c|}{ Independent variables } \\
\hline INCOME & $\begin{array}{l}\text { Indicator variable that takes the value of one if the target price forecast is based } \\
\text { on an income valuation approach, zero otherwise }\end{array}$ \\
\hline MARKET & $\begin{array}{l}\text { Indicator variable that takes the value of one if the target price forecast is based } \\
\text { on a market valuation approach, zero otherwise }\end{array}$ \\
\hline$H Y B R I D$ & $\begin{array}{l}\text { Indicator variable that takes the value of one if the target price forecast is based } \\
\text { on a hybrid valuation approach, zero otherwise }\end{array}$ \\
\hline SOTP & $\begin{array}{l}\text { Indicator variable that takes the value of one if the target price forecast is entirely } \\
\text { based on a sum of the parts valuation, zero otherwise }\end{array}$ \\
\hline SOTP_hybrid & $\begin{array}{l}\text { Indicator variable that takes the value of one if the target price forecast is entirely } \\
\text { based on a sum of the parts valuation, which is solely based on the hybrid } \\
\text { approach, zero otherwise }\end{array}$ \\
\hline \multicolumn{2}{|l|}{ Control variables } \\
\hline$S I Z E$ & Natural logarithm of the market capitalization at the fiscal year end \\
\hline$P T B$ & $\begin{array}{l}\text { Price-to-book ratio, calculated as the market value of common equity divided by } \\
\text { the book value of common equity at the fiscal year end }\end{array}$ \\
\hline GROWTH & $\begin{array}{l}\text { Sales Growth, calculated as total revenue at the end of the fiscal year } t \text { divided by } \\
\text { the total revenue at the end of the fiscal year } t-1 \text {, minus one }\end{array}$ \\
\hline FOLLOW & $\begin{array}{l}\text { Natural logarithm of the number of financial analysts providing at least one target } \\
\text { price forecast for a firm in year } t\end{array}$ \\
\hline VOLAT & $\begin{array}{l}\text { Natural logarithm of the price volatility, a measure of a stock's average annual } \\
\text { price movement above or below a mean price for each year }\end{array}$ \\
\hline BOLDNESS & $\begin{array}{l}\text { Measure of the boldness of the target price, calculated as the difference between } \\
\text { the target price and the share price at the forecast issue date scaled by the share } \\
\text { price at the forecast issue date }\end{array}$ \\
\hline$R O A$ & Net income divided by total assets at the fiscal year end, multiplied by 100 \\
\hline
\end{tabular}


Table 2 (continued)

\begin{tabular}{ll}
\hline Variable & Definition \\
\hline LEV & Total debt divided by total assets at the end of the fiscal year \\
PEERS & $\begin{array}{l}\text { Number of the sampled firms (DAX-firms) in each industry, using the 12-indus- } \\
\text { try classification by Fama and French (2019) } \\
\text { Number of Stoxx Europe 600-firms in each industry, using the 12-industry clas- } \\
\text { sification by Fama and French (2019) }\end{array}$ \\
SEGMENTS & $\begin{array}{l}\text { Number of reporting segments according to IFRS 8, as reported in the consoli- } \\
\text { dated financial statement of firm j at the end of the fiscal year } t\end{array}$ \\
EPS_Acc & Absolute difference between actual EPS and median EPS forecast scaled by stock \\
price at the end of the year & Broker fixed effects for 35 different brokerage houses, as listed in Table 1 Panel \\
BROKER & B
\end{tabular}

This table provides variable definitions. All variables are winsorized at the 1st and 99th percentile

MARKET or HYBRID that take the value of one if the target price is determined by the income, market or hybrid valuation approach, respectively, and zero otherwise. Regarding $\mathrm{H2}$, it refers to the dummy variable SOTP that takes the value of one if the target price bases on a sum of the parts valuation approach and zero otherwise.

Prior research has identified several important determinants for target price accuracy, which we want to control for to isolate the effects induced by analysts' valuation approach choice. Extant literature emphasize that analysts' forecast accuracy is related to firms' information environment, i.e. level of disseminated information via public and private channels. They suggest profitability and growth opportunities to be important factors determining firms' information environment (e.g., Asquith et al. 2005; Lang and Lundholm 1993; Bhushan 1989; Demirakos et al. 2010). ROA (return on assets) is the net income divided by total assets at the fiscal year end, multiplied by 100 . PTB (price-to-book ratio) is calculated as the market value of common equity divided by the book value of common equity at the fiscal year end. The variable GROWTH measures the sales growth as total revenue at the end of the fiscal year $t$ divided by the total revenue at the end of the fiscal year $t-1$. Both PTB and GROWTH capture differences in growth opportunities across analyzed firms. A stronger information environment by a firm is likely to improve analysts' information environment and, hence, his/her ability to better value the company and provide accurate forecasts.

Next, we include FOLLOW as the natural logarithm of the number of financial analysts providing at least one target price forecast for a firm in year $t$. This variable approximates analyst incentives and intensity of competition, as these enhance analysts' motivation to value the company accurately (Bilinski et al. 2013; Hope 2003; Lys and Soo 1995; Lang and Lundholm 1996). Financial analysts may value firms with well comparable firms in its industry better. Therefore, we include the variable PEERS as the number of the sampled firms in each industry, using the 12-industry 
classification by Fama and French (2019) (Demirakos et al. 2010). ${ }^{6}$ Kerl (2011) argues that the target price accuracy might be conditional on the volatility of share prices since highly volatile and diverging stock prices across analyzed firms might challenge analysts when forecasting target prices. VOLAT is additionally considered to be a proxy for risk, as higher levels of risk make it more difficult to estimate target prices (Bradshaw et al. 2013; Kerl 2011). VOLAT represent the natural logarithm of the price volatility, which is a measure of a stock's average annual price movement above or below a mean price for each year. Firms' financial leverage is also considered as a risk proxy that captures difficulties in forecasting earnings (Asquith et al. 2005; Kaustia et al. 2009). LEV is calculated as the total debt divided by total assets at the end of the fiscal year.

We additionally consider target price boldness to control for divergences between the current market consensus and analyst expectations about firms' fundamental value since greater boldness is likely to result in less accurate target price forecasts (Demirakos et al. 2010). BOLDNESS is calculated as the difference between the target price and the share price at the forecast issue date scaled by the share price at the forecast issue date. Moreover, prior research emphasize that analysts use their own earnings estimates among other predicted firm fundamentals as valuation model input when determining firms' fundamental value (Gleason et al. 2013; Ramnath et al. 2008; Schipper 1991). Therefore, analysts might use different input data for the same valuation approach and the accuracy of the input data might vary as well. The accuracy of an analyst's input data in determining price targets, and consequently her target price accuracy, highly depends on her general forecasting ability. Following this rational, we include the variable EPS_Acc as earnings forecast accuracy in our model to control for an analyst's general forecasting ability and to count for the quality of an analyst's input data. ${ }^{7} E P S \_A c c$ is calculated as the absolute difference between actual EPS and median EPS forecast scaled by stock price at the end of the year.

In addition to firm-, analyst-, and industry-specific control variables, we include broker and year fixed effects to hold differences across brokerage houses and years constant. This aims to ensure that the estimated coefficients indicate the change in analysts' target price accuracy associated with the application of a certain valuation technique. To mitigate the influence of outliers, all variables are winsorized at the $1^{\text {st }}$ and $99^{\text {th }}$ percentile. Table 2 provides definitions of dependent and independent variables.

\footnotetext{
${ }^{6}$ Note that we find virtually unchanged results if we use the variable PEERS_stoxx instead, indicating industry peers in Stoxx Europe 600. PEERS_stoxx is used as part of probit regressions in Sect. 5.3.

7 We thank an anonymous reviewer for this suggestion.
} 


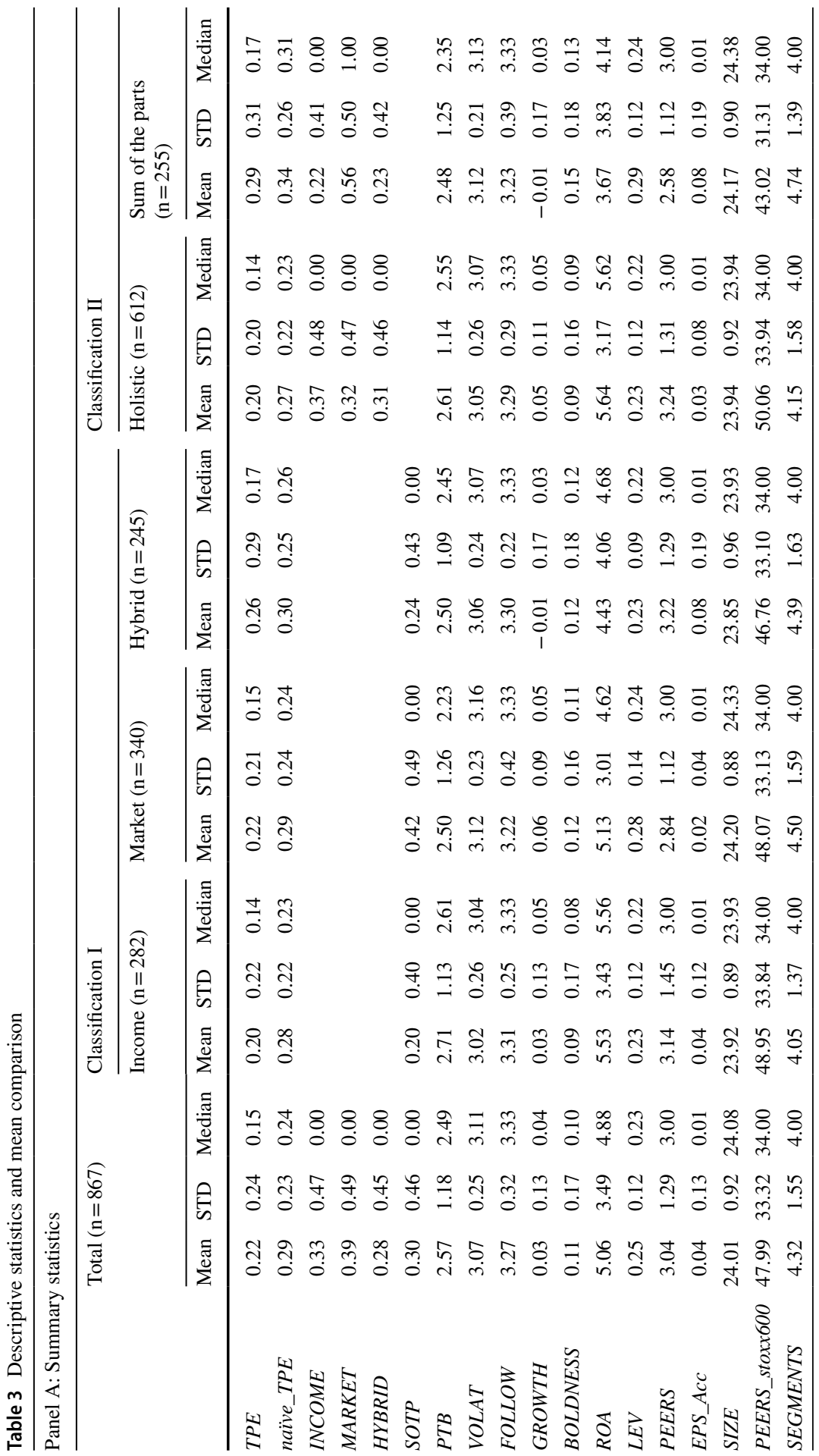




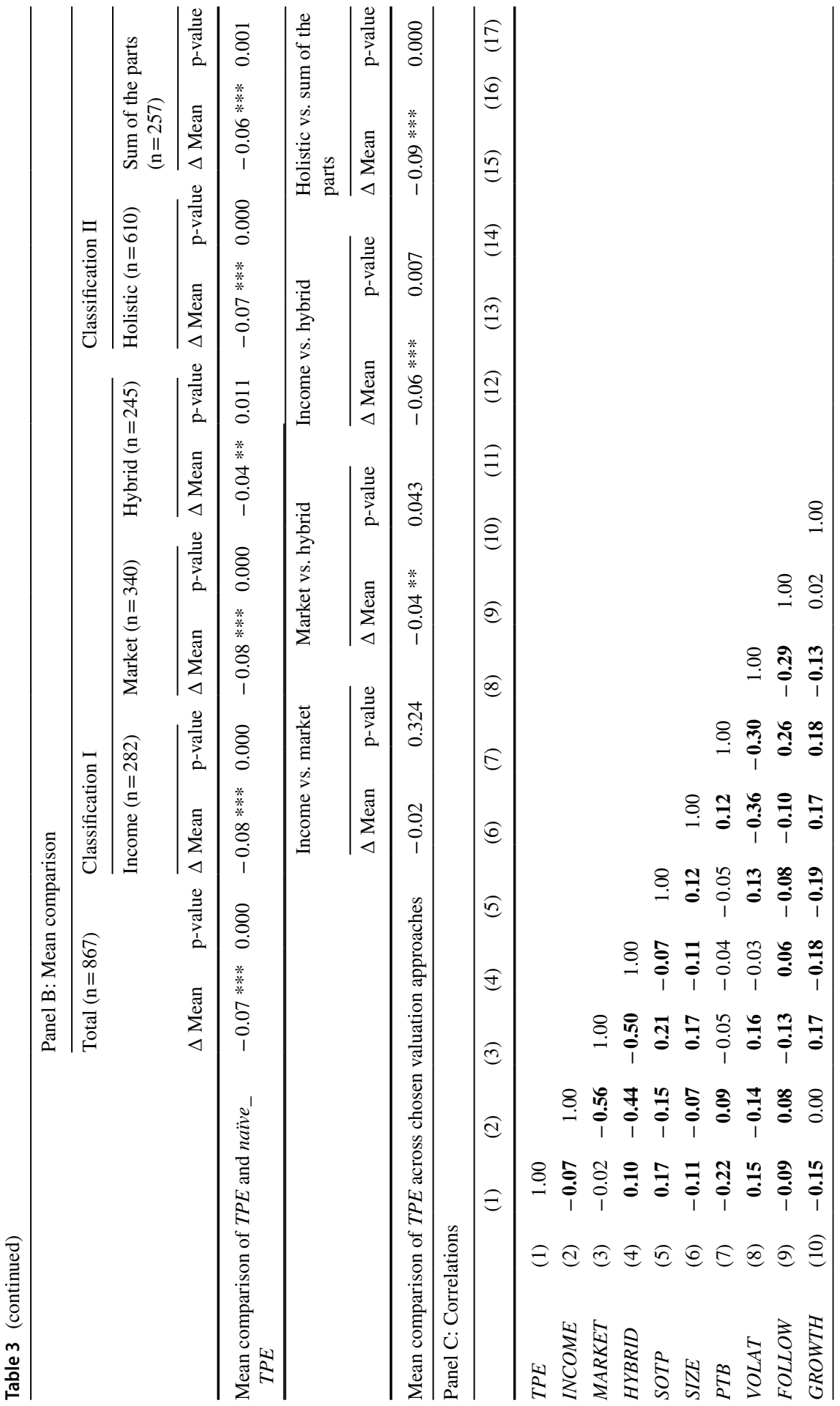




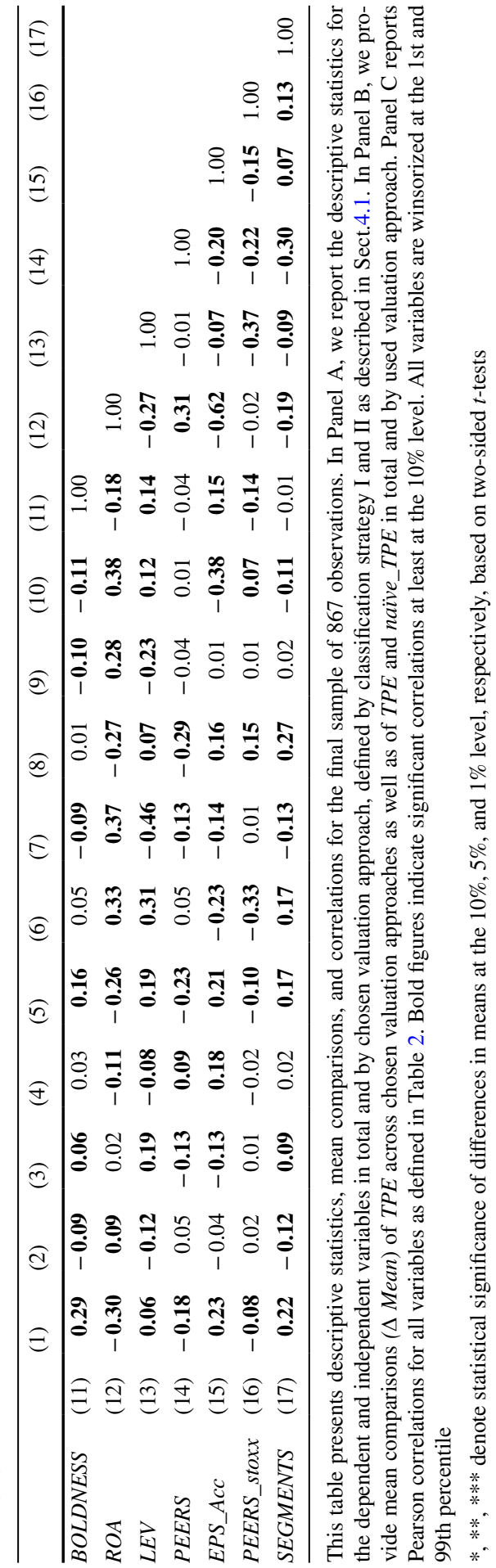




\section{Empirical results}

\subsection{Descriptive statistics and mean comparison}

Panel A of Table 3 reports summary statistics in total, by classification strategy I (income, market, and hybrid approach), and by classification strategy II (holistic and SOTP approach). In addition, Panel B of Table 3 presents mean comparisons, using $t$-tests that compare the means of target price errors across the identified groups as well as between analysts forecast errors and naïve forecast errors. We first compare the target price accuracy of financial analysts (TPE) with those of naïve forecasts (naïve_TPE) that merely extrapolate past returns into the future (see Table 2). If the naïve forecasts are less accurate than the target price forecasts of financial analysts, the latter clearly has information value for investors and other capital market participants (Bilinski et al. 2013; Grüber 2015; Sengupta 1998). We find that the mean analyst TPE is significantly lower than the mean naïve_TPE for the total sample as well as in all subtotals, grouped by valuation approaches employed. Thus, analysts' target prices offer value for capital market participants and are better suited to formulate price targets than naïve extrapolations of historical returns.

The total sample has a mean (median) TPE of $0.22(0.15)$, where the mean (median) TPE based on an income valuation approach is $0.20(0.14)$, market valuation approach $0.22(0.15)$, and hybrid approach $0.26(0.17)$. The mean comparisons show that target price errors do not significantly differ when analysts apply the income or market approach to determine the fundamental value of the company. However, the mean TPE is significantly lower when applying the income (mean difference of -0.04 ; p-value: 0.043 ) or market approach (mean difference of -0.06; p-value: 0.007 ) compared to the hybrid approach, suggesting that income and market approaches outperform hybrid calculations. Switching the perspective to the second classification, we find that the mean TPE is significantly lower when analysts use holistic valuation techniques (0.20) rather than SOTPvaluations (0.29) to formulate price targets (mean difference of -0.09 ; p-value: 0.000). Contrary to our expectation (H2), the latter approach, therefore, seems not to perform better than the holistic valuation approach.

In Panel $\mathrm{C}$ of Table 3, we show correlations for all included variables for the total sample. The variables INCOME and MARKET are negatively correlated with $T P E$, whereby only the correlation between INCOME and TPE is statistically significant at least at the $10 \%$ level. HYBRID and SOTP are significantly positively correlated with $T P E$, suggesting higher target price errors when applying hybrid instead of income and market approaches or SOTP instead of holistic approaches. These correlations are in line with the results of the mean comparisons, but contradictory to our expectations as hypothesized. The high correlations between INCOME, MARKET, and HYBRID are straightforward and result from the classification of the observations into one of these groups. There is a moderate negative correlation between $P T B$ and $L E V(-0.46)$, indicating that firms' financial leverage is smaller the more the firm is profitable. ROA and EPS_Acc are highly 


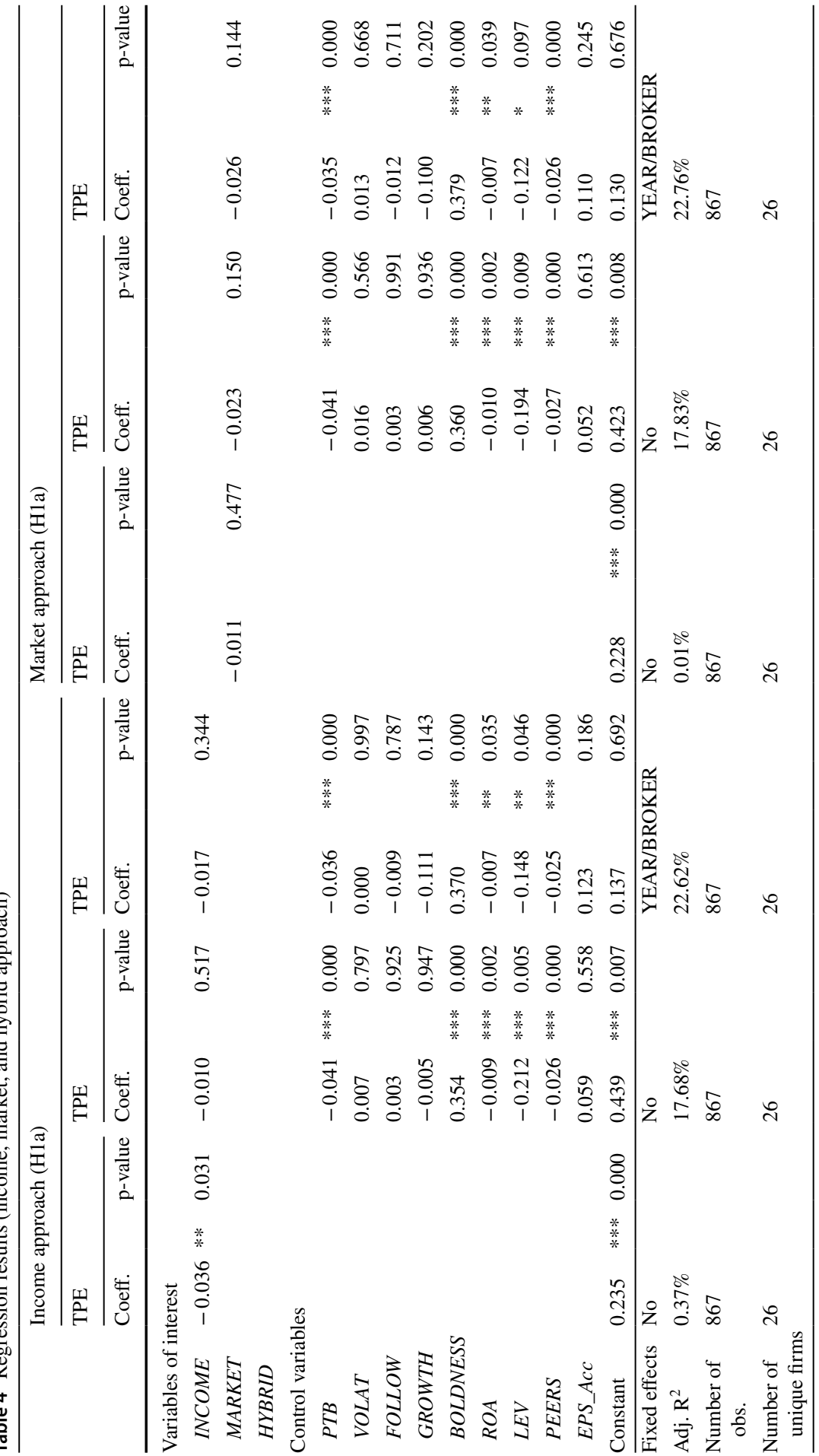




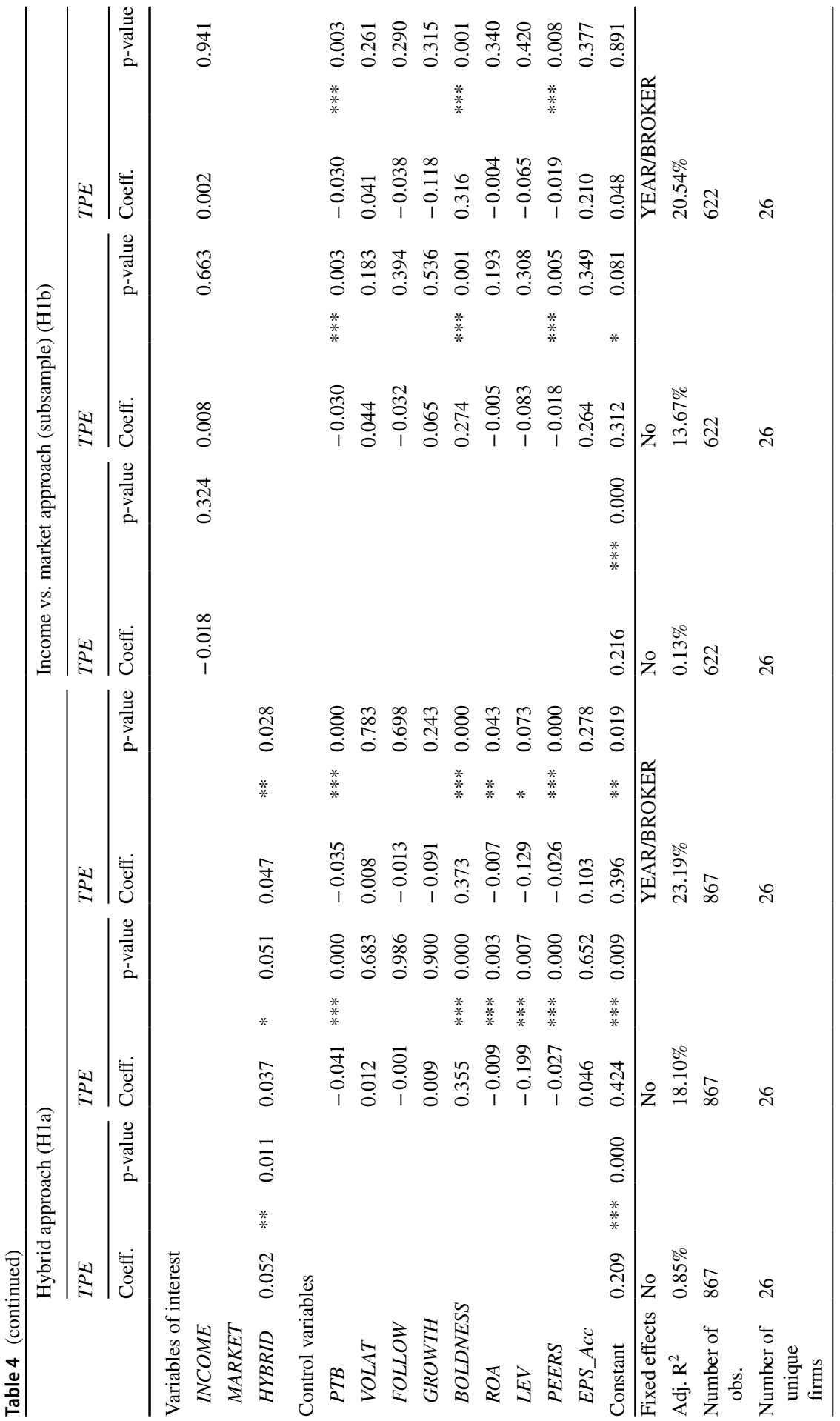




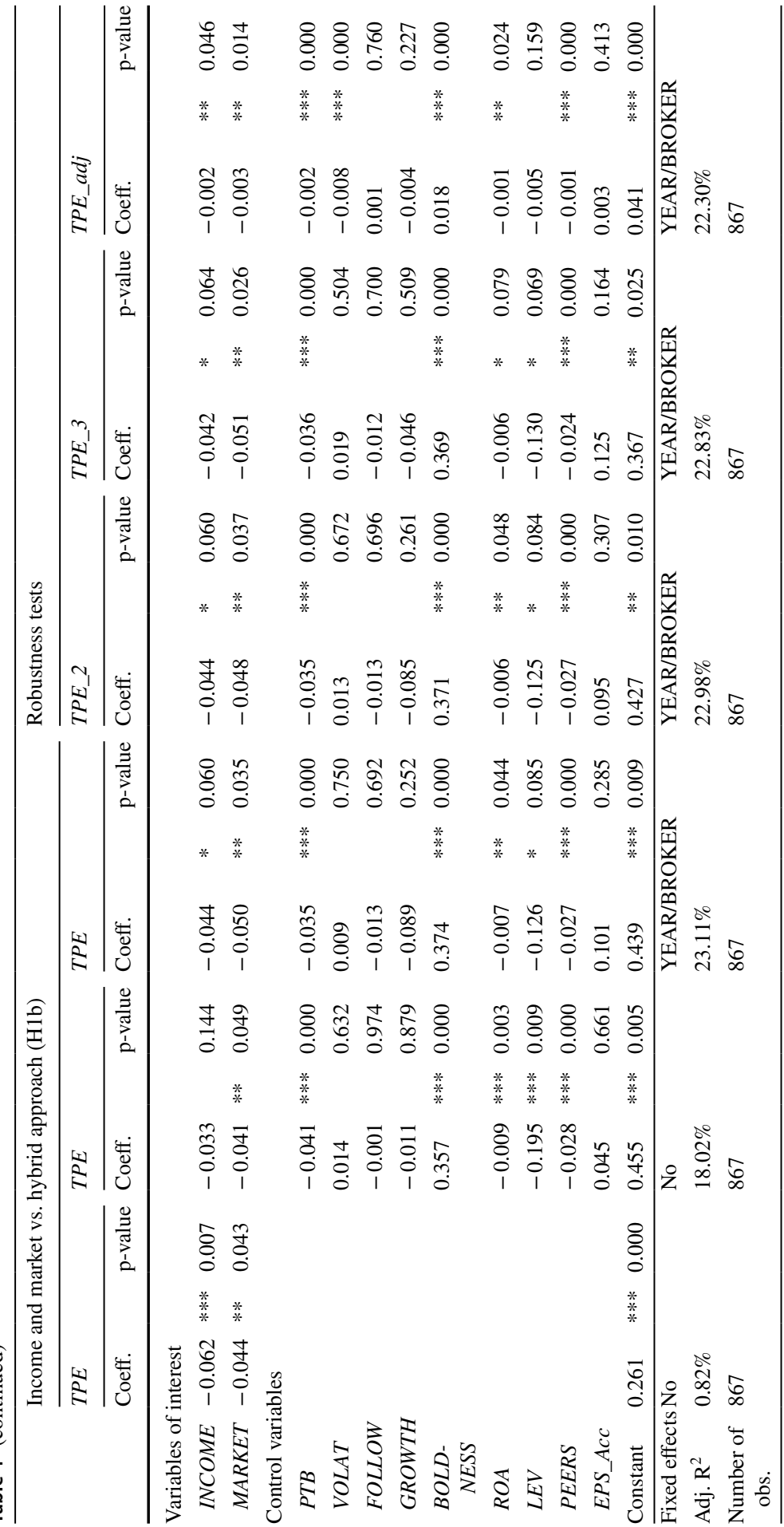




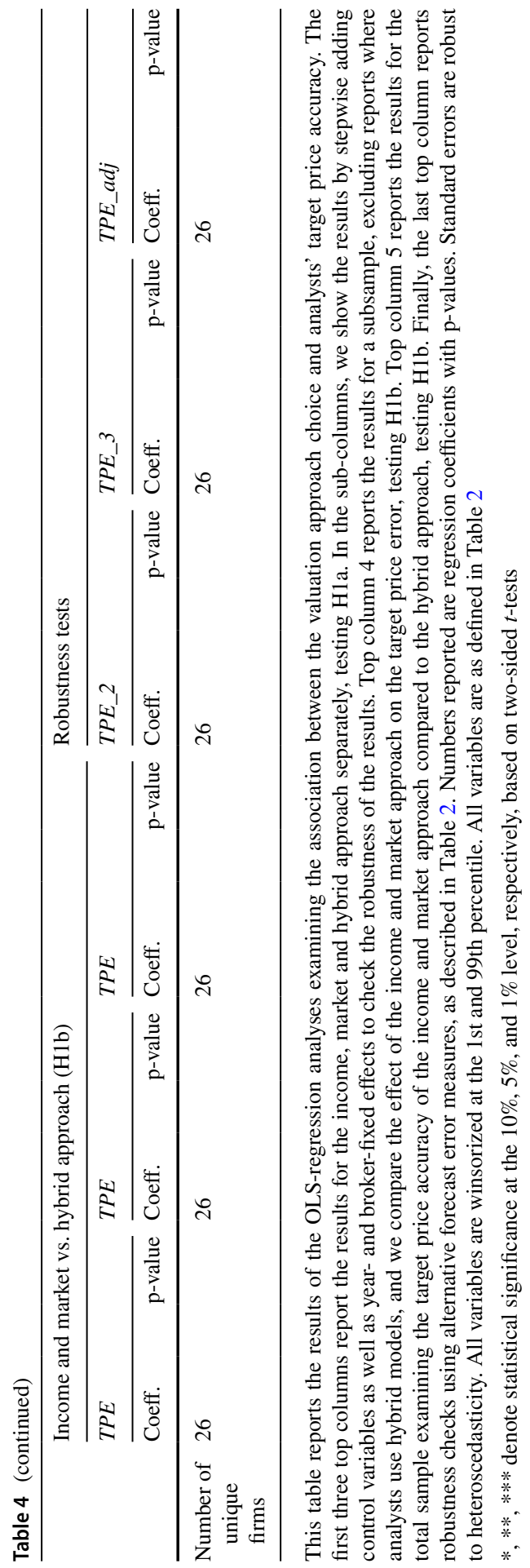


negatively correlated, suggesting that analysts predict EPS for profitable firms more accurately. This is consistent with the notion that more profitable firms have a lager information environment, supporting analysts in predicting future values. However, the Pearson correlations do not indicate other serious multicollinearity concerns or strong correlations $(> \pm 0.5)$.

\subsection{Multivariate results}

Table 4 presents the results of the OLS-regression estimating Eq. (2) to test $\mathrm{HIa}$ and $H 1 \mathrm{~b}$, concerning the association between analysts' target price accuracy and the usage of the income, market, and/or hybrid valuation approach. We first estimate the effects of certain valuation approaches on target price accuracy separately and then compare the three approaches in terms of their forecasting quality. With regard to each top column (e.g., income approach) in Table 4, sub-column (1) presents the results of the regressions without control variables and fixed effects, sub-column (2) with control variables, and sub-column (3) with both control variables and fixed effects. This aims to check whether the results change when controlling stepwise for firm- and industry-specific factors and then for year- and broker-specific factors. Since the regression results do not significantly differ across the three sub-columns and remain robust in all specifications, we focus on the latter sub-columns when interpreting the results. The overall fits of the regression models are comparable to prior studies dealing with target prices, as the main models have adjusted $\mathrm{R}^{2}$, $\mathrm{s}$ between $20 \%$ and $23 \%$.

Top columns 1, 2, and 3 present the results for the isolated analyses of the valuation approaches (testing $\mathrm{Hla}$ ). The variable of interest is the dummy variable for the income, market, or hybrid approach in each regression. The coefficients for INCOME and MARKET are statistically insignificant, and therefore suggest that there is no association between the usage of the income or market valuation approach and the target price accuracy. However, the coefficient on HYBRID is positive and statistically significant at the 5\%-level, also after including control variables and fixed effects. This result suggests that hybrid valuations lead to higher price target errors than income and market valuation techniques. Next, we compare the three approaches and test $H 1 b$. Top column 4 reports the results for a subsample, excluding reports where analysts use hybrid models, and we compare the effect of the income and market approach on the target price error. The coefficient on INCOME is insignificant and indicate no difference between the income and market approach in terms of target price accuracy, as already shown by univariate analyses. Top column 5 and 6 report the results for the total sample examining the target price accuracy of the income and market approach compared to the hybrid approach (testing $H 1 b$ ). Note that top column 6 reports robustness tests using alternative measures for analysts' target price accuracy, as described in Sect. 4.3. Interestingly, the coefficient on INCOME (-0.044) and MARKET (-0.050) are negative and statistically significant at the 5\%- and 10\%-level, respectively. This result remains robust when we use the alternative measures for target price accuracy TPE_2,TPE_3, and TPE_adj. Thus, we provide evidence that the income and market approach lead to significantly 
higher target price accuracy than the hybrid approach. The coefficients on the control variables are broadly consistent with prior studies described in Sect. 4.4 since firm's profitability (PTB and ROA) and number of industry peers (PEERS) are associated with more accurate target price forecasts. BOLDNESS is positively correlated with TPE, indicating that greater boldness is likely to result in less accurate target price forecasts (Demirakos et al. 2010). However, contrary to our expectation, VOLAT, FOLLOW, and GROWTH are not associated with TPE. The reason might be that we only consider DAX30 companies in our setting that are characterized by similar volatility, number of analysts following and growth opportunities.

Consistent with Asquith et al. (2005) or Demirakos et al. (2010), we find that the application of either a multi-period income calculation or a single-period multiple technique is not associated with the target price accuracy. Our study shows that the income and market approach do not differ in forecasting performance. In contrast, Gleason et al. (2013) predicted that the quality of target prices improves significantly when analysts appear to use fundamental valuations rather than simple heuristics. However, as we contribute to this by also analyzing hybrid valuations, we show that the hybrid valuation approach is significantly associated with less accurate price targets. Using different valuation approaches typically provides analysts with a range of possible valuations for a particular company. Applying subjective weightings to the different results is prone to (conscious or unconscious) manipulation and allows analysts to easily tweak the valuation by adjusting the weightings. ${ }^{8}$ Ceteris paribus, this results in less accurate company valuations. This is contrary to the descriptive findings of Imam et al. (2013), who suggest that price targets are attained more often when analysts combine cash flow and accrual based models. Overall, we provide evidence that the choice of valuation approach when formulating target prices has an impact on the accuracy of target prices. Both univariate and multivariate results emphasize that the income and market approach lead to more accurate target prices compared to the hybrid approach, which combines the results of income and market calculations. Thus, we are able to reject both the null-hypotheses $H 1 a$ and $H 1 b$.

Table 5 reports the results of the OLS-regression estimating Eq. (2) to test $H 2$, concerning the association between analysts' target price accuracy and the usage of the SOTP or holistic valuation approach. The coefficient on the dummy variable SOTP (0.036) is positive and statistically significant at the $10 \%$-level, emphasizing that the SOTP valuation leads to lower target price accuracy compared to the holistic valuation approach. This result remains robust when we use the alternative measures for target price accuracy $T P E \_2, T P E \_3$, and $T P E \_a d j$. In contrast to prior studies by Paarz (2011) and Chlomou and Demirakos (2020), we are able to find a significant association between the SOTP valuation approach and analysts' target price accuracy and, therefore, to contribute to the literature. As the SOTP valuation

\footnotetext{
${ }^{8}$ Arguably, both market based (e.g. when defining the peer set) and income based (e.g. when defining the cost of capital or terminal growth rates) approaches include subjective elements. However, analysts typically try to derive these items by referring to company guidance and disclosures or macro data. The weightings analysts apply when using hybrid models are typically not objectively derived but rather set by the respective analyst, thereby further adding subjectivity to the company valuation conducted.
} 


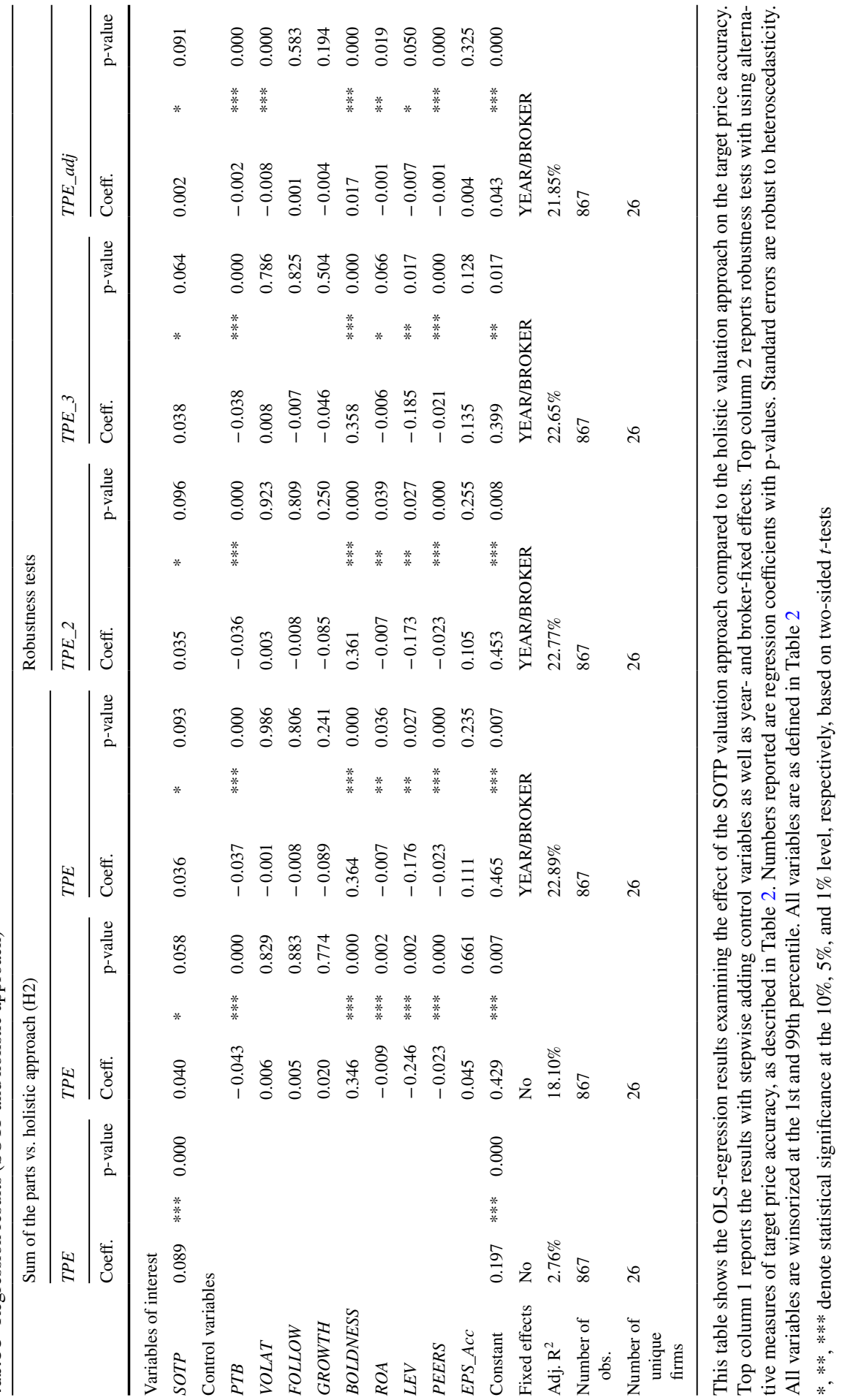


leads to higher target price errors than the holistic approach, we reject $H 2$. This is in line with Chlomou and Demirakos (2020) who also find that DCF leads to more precise target prices, employing a similar metric to measure forecast accuracy.

This result also appears to be highly relevant for practitioners when applying and judging company valuations derived from SOTP models or conducting due diligence on companies operating across different business segments. Out of the 257 SOTP target prices in the sample, 167 (or 65\%) overvalue the security (i.e. the share price at the end of the forecasting period is lower than the target price), whereas just 90 (or 35\%) of the SOTP target prices undervalue the respective company. Interestingly, this deviates significantly from the distribution of the entire sample (867 target prices) as $52 \%(48 \%)$ of the analysts overvalue (undervalue) the security, and even more for all non-SOTP based target prices with $47 \%$ (53) of target prices exceeding (falling short of) the share price at the end of the forecasting period. You (2014) finds that conglomerates face incentives to shift profits to business units operating in industries with higher valuation multiples and thereby, ceteris paribus, SOTP models generate systematically overpriced valuations if analysts do not adequately account for this earnings management behavior. Our results provide further evidence to the claim that the SOTP approach tends to result in inflated company valuations.

\subsection{Additional analyses}

\subsubsection{Determinants of valuation approach choice}

In the main regressions, we control for several factors that are likely to affect the target price accuracy, but do not analyze factors that might influence analysts' valuation approach choice, and consequently their target price accuracy. In Sect. 2 and 4.4, we have discussed several important determinants of both valuation method choice and target price accuracy. However, to additionally contribute to exiting literature, we examine what drives the differences in valuation approach choice since this choice - and the associated trade-off faced by analysts - is important to understand observed differences between valuation approaches. ${ }^{9}$ For this purpose, we estimate the following probit regression:

$$
\begin{aligned}
P\left({\text { VALUATION }=1)_{i j t}}\right. & =\Phi\left(\beta_{0}+\beta_{1} \text { SIZE }_{j t}+\beta_{2} \text { PTB }_{j t}+\beta_{3} \text { VOLAT }_{j t}+\beta_{4} \text { FOLLOW }_{j t}\right. \\
& +\beta_{5} \text { GROWTH }_{j t}+\beta_{6} \text { PEERS_stoxx }_{j t}+\beta_{7} \text { SEGMENTS }_{j t}+\beta_{8} \text { ROA }_{j t}+\beta_{9} L_{E V} V_{j t} \\
& \left.+\sum \gamma_{i} \text { BROKER }_{i}+u_{j t}\right)
\end{aligned}
$$

The subscript $i$ refers to a brokerage house, $j$ refers to a firm and $t$ refers to a year. VALUATION indicates whether an analyst applies the income, market, or hybrid approach regarding $\mathrm{H} 1$, and the SOTP approach regarding H2. Demirakos et al. (2010) suggest that firm size (SIZE), risk level (VOLAT), sales growth $(G R O W T H)$, and number of industry peers (PEERS_stoxx) influence analysts' choice whether to use a DCF or PE model. Thus, we include these factors in our

\footnotetext{
9 We thank the editor and an anonymous reviewer for this suggestion.
} 


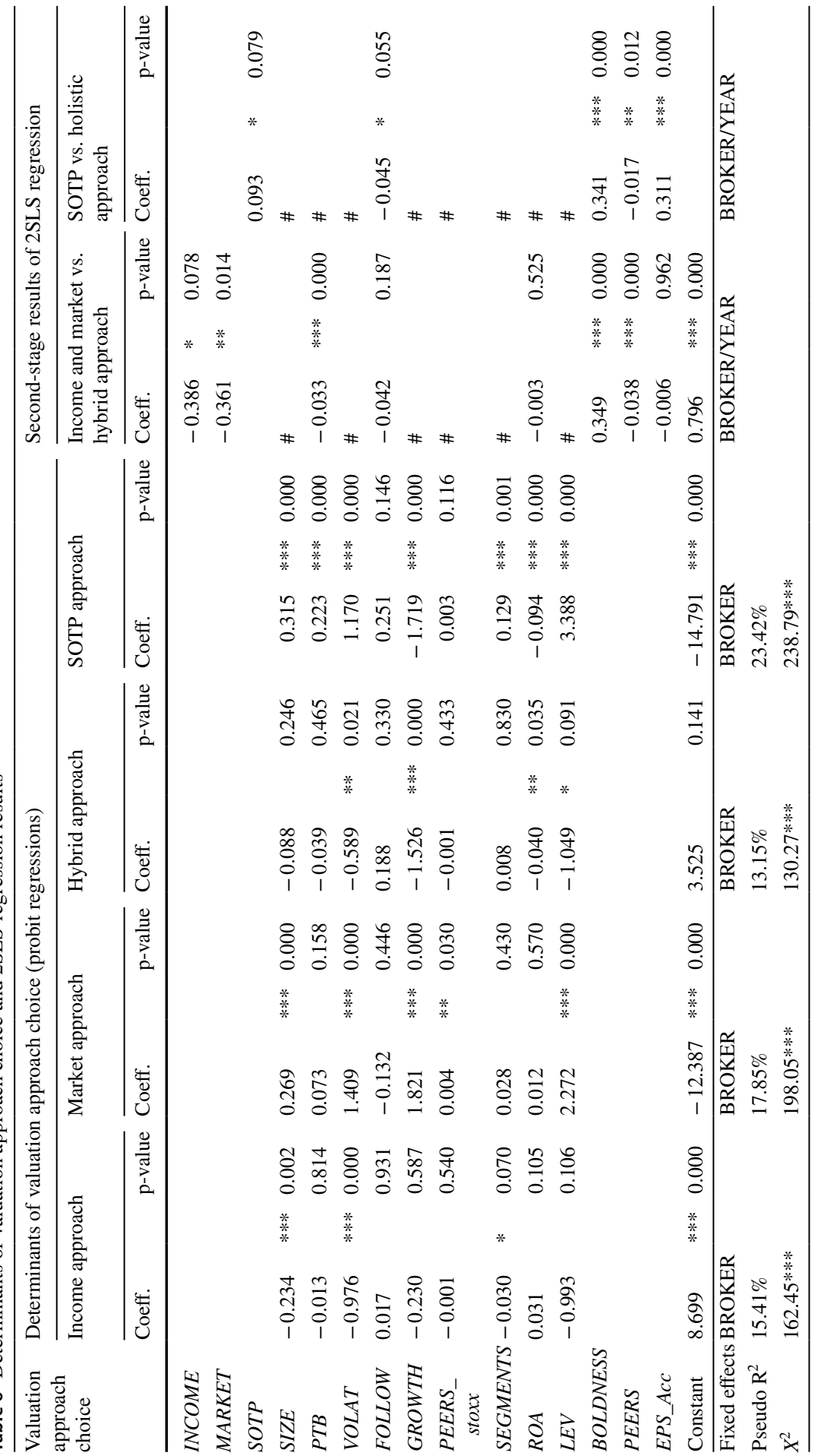




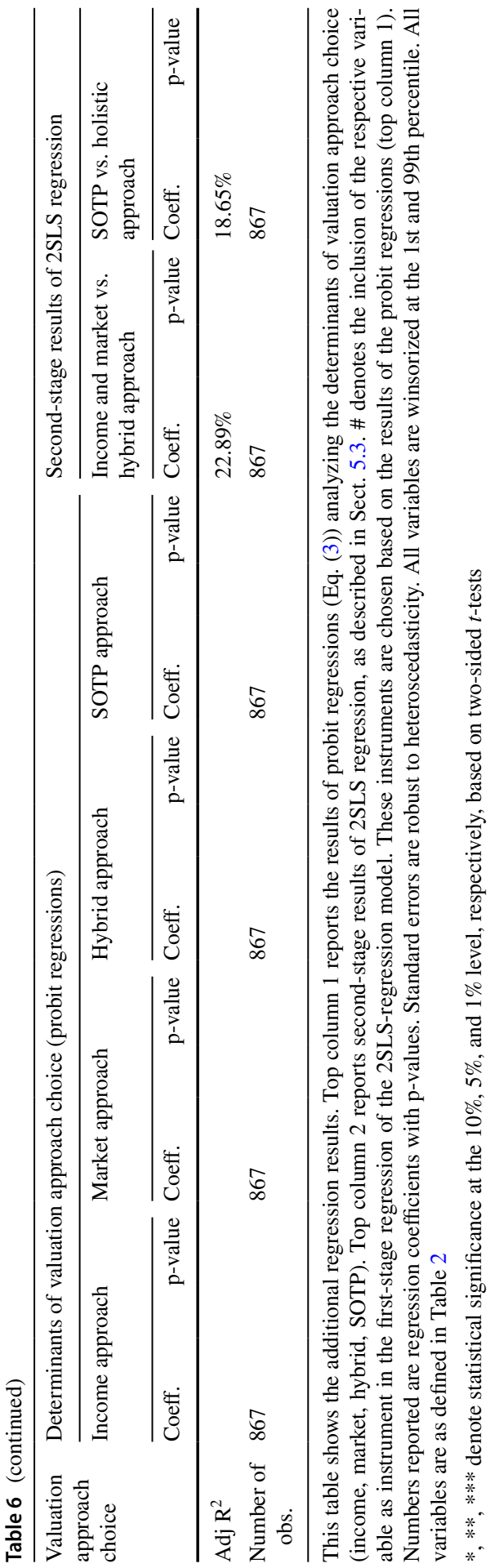


probit model. SIZE is computed as the natural logarithm of the market capitalization at the fiscal year end, and controls for firm size. PEERS_stoxx indicates the number of industry peer firms in the Stoxx Europe 600, using the 12-industry classification by Fama and French (2019). Furthermore, we include ROA and $L E V$. We also consider the number of reporting segments according to IFRS 8 (SEGMENTS), price-to-book ratio $(P T B)$, and stock-price volatility (VOLAT) to approximate the complexity of valuation. FOLLOW is used as a proxy for analysts' incentives and intensity of competition. To consider differences across brokerage houses, we include broker fixed effects in Eq. (3).

Table 6 reports the results of the probit regressions. We provide evidence that firm size, level of risk (VOLAT, $L E V$ ), profitability (GROWTH), number of industry peers, and number of reporting segments determine the choice of valuation approach. Particularly, analysts are more likely to apply the market approach if the firm is larger, more profitable, riskier, and has more industry peers. Contrary, analysts are more likely to choose the income approach for smaller, less risky firms with fewer reporting segments. Moreover, when firms are smaller, less risky, and less profitable, analysts are more likely to apply the hybrid approach. Regarding the second classification strategy, the larger, riskier, and more profitable the firm, the more likely the analysts tend to apply a SOTP approach. The number of reporting segments also determines this choice. Therefore, we provide additional evidence that analysts' choice of valuation approach is determined by several factors, and this choice has an effect on analysts' target price accuracy, as our main results emphasize.

\subsubsection{Two-stage least square regression}

Since we have identified determinants of both valuation approach choice and target price accuracy, we additionally analyze the robustness of our main results by conducting two-stage least square regressions (2SLS). Hereby, the selection of instruments for the first stage regression bases on the probit regression results. Thus, we use SIZE, VOLAT, GROWTH, PEERS_stoxx, SEGMENTS, and LEV as instruments for the instrumented variables INCOME and MARKET. We additionally control for PTB, FOLLOW, ROA, BOLDNESS, PEERS, EPS_Acc, and broker/year fixed effects in the second-stage regression, as these factors might influence the target price accuracy. When comparing the SOTP and holistic approach, we use SIZE, PTB, VOLAT, GROWTH, PEERS_stoxx, SEGMENTS, ROA, and $L E V$ as instruments for the instrumented variable $S O T P$. In the respective secondstage regression, we control for FOLLOW, BOLDNESS, PEERS, EPS_Acc, and broker/year fixed effects.

Table 6 reports the results of the 2SLS-regressions. The main results and conclusions are virtually unchanged. The income and market approach outperform the hybrid approach in terms of target price accuracy. The SOTP technique leads to less accurate target price forecasts, relative to the holistic valuation approach. 
Table 7 Additional regression results (SOTP framework)

\begin{tabular}{|c|c|c|c|c|c|c|c|c|c|}
\hline & \multicolumn{9}{|c|}{ Sum of the parts solely based on hybrid vs. income and market approach } \\
\hline & \multicolumn{3}{|l|}{$T P E$} & \multicolumn{3}{|l|}{$T P E$} & \multicolumn{3}{|l|}{$T P E$} \\
\hline & Coeff. & & p-value & Coeff. & & p-value & Coeff. & & p-value \\
\hline \multicolumn{10}{|l|}{ Variables of interest } \\
\hline SOTP_hybrid & 0.181 & $* * *$ & 0.003 & 0.098 & $*$ & 0.078 & 0.093 & $*$ & 0.085 \\
\hline \multicolumn{10}{|l|}{ Control variables } \\
\hline$P T B$ & & & & -0.094 & $* * *$ & 0.000 & -0.078 & $* * *$ & 0.000 \\
\hline VOLAT & & & & -0.025 & & 0.756 & -0.065 & & 0.374 \\
\hline FOLLOW & & & & 0.046 & & 0.422 & 0.031 & & 0.525 \\
\hline GROWTH & & & & 0.126 & & 0.329 & -0.004 & & 0.976 \\
\hline BOLDNESS & & & & 0.461 & $* * *$ & 0.000 & 0.465 & $* * *$ & 0.000 \\
\hline$R O A$ & & & & -0.033 & $* * *$ & 0.000 & -0.025 & $* * *$ & 0.000 \\
\hline$L E V$ & & & & -0.731 & $* * *$ & 0.000 & -0.534 & $* * *$ & 0.002 \\
\hline PEERS & & & & -0.040 & $* * *$ & 0.009 & -0.036 & $* *$ & 0.015 \\
\hline EPS_Acc & & & & -0.538 & $* * *$ & 0.001 & -0.340 & $* *$ & 0.020 \\
\hline$\underline{\text { Constant }}$ & 0.246 & $* * *$ & 0.000 & 0.831 & $* *$ & 0.016 & 0.735 & $* *$ & 0.017 \\
\hline Fixed effects & No & & & No & & & YEAR & & \\
\hline Adj. $\mathrm{R}^{2}$ & $5.46 \%$ & & & $30.33 \%$ & & & $39.41 \%$ & & \\
\hline Number of obs. & 255 & & & 255 & & & 255 & & \\
\hline Number of unique firms & 22 & & & 22 & & & 22 & & \\
\hline
\end{tabular}

This table shows the OLS-regression results examining the effect of the SOTP valuation when it bases solely on hybrid approaches compared to the SOTP valuation when it bases on income and market approaches on the target price accuracy. We report the results with stepwise adding control variables as well as year-fixed effects. Numbers reported are regression coefficients with p-values. Standard errors are robust to heteroscedasticity. All variables are winsorized at the 1st and 99th percentile. All variables are as defined in Table 2

$*$, **, *** denote statistical significance at the $10 \%, 5 \%$, and $1 \%$ level, respectively, based on two-sided $t$-tests

\subsubsection{SOTP valuation framework}

The main results emphasize that SOTP approaches underperform compared to holistic calculation, and that income and market models perform significantly better than hybrid calculation. We expand on this by analyzing whether the target price of the SOTP approach differs when SOTP is based on the hybrid approach rather than solely on the market or income approaches to value all the individual business units of a firm. For this purpose, we only consider the 255 SOTP observations in our sample and categorize whether the SOTP valuation bases on the market, income, or hybrid approach. This yields 142 observations with SOTP-market approach, 55 with SOTP-income approach, and 58 with SOTP-hybrid approach. We introduce the variable SOTP_hybrid that indicates whether the target price is determined by a SOTPhybrid calculation. Table 7 reports the additional results estimating Eq. (2), using the newly introduced variable of interest. The regression results indicate that the 
target price accuracy is significantly higher when analysts use hybrid calculations in the SOTP valuation framework rather than solely income or market approaches. We find virtually unchanged results (untabulated) if we compare the forecast accuracy of only the SOTP-market approach to the SOTP-hybrid approach or of the SOTPincome approach to the SOTP-hybrid approach. Therefore, we provide evidence that income and market approaches dominate hybrid approaches in terms of target price accuracy both at holistic and a SOTP level.

\section{Conclusion}

This study investigates whether the choice of the valuation approach is associated with the target price accuracy of sell-side financial analysts. Our univariate and multivariate results emphasize that there is a significant association between the valuation approach choice and target price accuracy, contributing to both research and practice. Specifically, we provide evidence that the multi-period income approach and the single-period market approach lead to significantly higher target price accuracy than the hybrid approach, which combines the results of the first two approaches. The attempt to objectify valuation by combining income and market based methods leads to less accurate results, arguable because the application of not objectively derived weightings adds further subjectivity to the valuation assignment. We also find that the SOTP valuation approach leads to significantly higher target price errors than the holistic valuation of a company. Given the frequent usage of SOTP particularly in complex valuations assignments, this result is also of highest relevance for practitioners. In additional tests, we show that the market and income approaches also dominate the hybrid approach in predicting target prices in the SOTP valuation framework. Moreover, we provide evidence that firm size, level of risk, profitability, number of industry peers, and number of reporting segments under IFRS 8 determine the choice of valuation approach.

Our study is subject to several caveats. First, we conduct a content analysis, implicitly assuming that financial analysts communicate the valuation methods they actually use to formulate price targets. However, one could argue that the target price is based on several valuation approaches, but the analyst prefers to communicate only one particular approach. Second, our sample covers German companies only. While we intentionally chose DAX30 companies, it may be questionable if our results hold true in another institutional context, e.g. for companies with less strict disclosure requirements or different accounting regimes. In addition, by focusing on DAX30 companies, results may not be representative of German companies of different size (in particular small and medium sized listed firms) which may limit generalizability of our findings. Third, while extensive effort was put into hand-collecting the data from the broker reports, our sample only covers target prices published over the course of 3.5 years (January 2014 and June 2017). Extending the time period (e.g. also including times of economic downturns) may lead to different results.

Our findings point towards different interesting avenues for further research. For instance, as our study suggests that the SOTP approach leads to less accurate 
valuation results, further research may focus on the factors that are associated with this pattern. We show that SOTP approaches tend to systematically inflate the target prices with $65 \%$ of the SOTP sample overstating the value of the respective company (vs. just $47 \%$ of non-SOTP target prices). Additional research may explore what percentage of SOTP approaches use conglomerate discounts to account for the earnings management and profit shifting incentive identified by You (2014) and how these target price compare to those SOTP approaches that are derived without any conglomerate adjustments. Understanding these dynamics would be a valuable contribution towards formulating more comprehensive SOTP valuation guidelines.

Funding Open Access funding enabled and organized by Projekt DEAL.

Open Access This article is licensed under a Creative Commons Attribution 4.0 International License, which permits use, sharing, adaptation, distribution and reproduction in any medium or format, as long as you give appropriate credit to the original author(s) and the source, provide a link to the Creative Commons licence, and indicate if changes were made. The images or other third party material in this article are included in the article's Creative Commons licence, unless indicated otherwise in a credit line to the material. If material is not included in the article's Creative Commons licence and your intended use is not permitted by statutory regulation or exceeds the permitted use, you will need to obtain permission directly from the copyright holder. To view a copy of this licence, visit http://creativecommons.org/licen ses/by/4.0/.

\section{References}

Asquith P, Mikhail MB, Au AS (2005) Information content of equity analyst reports. J Financ Econ 75(2):245-282

Barker RG (1999) The role of dividends in valuation models used by analysts and fund managers. Eur Account Rev 8(2):195-218

Bhushan R (1989) Firm characteristics and analyst following. J Account Econ 11(2-3):255-274

Bilinski P, Lyssimachou D, Walker M (2013) Target price accuracy: International evidence. Account Rev $88(3): 825-851$

Block S (1999) A study of financial analysts: practice and theory. Financ Anal J 55(4):86-95

Bonini S, Kerl A (2014) Subjective valuation and target price accuracy. Working Paper, available at: https://papers.ssrn.com/sol3/papers.cfm?abstract_id=2168856

Bonini S, Zanetti L, Bianchini R, Salvi A (2010) Target price accuracy in equity research. J Bus Financ Acc 37(9-10):1177-1217

Bradshaw M (2002) The use of target prices to justify sell-side analysts' stock recommondations. Account Horiz 16(1):27-41

Bradshaw M (2011) Analysts' forecasts: what do we know after decades of work? Working Paper, available at SSRN 1880339.

Bradshaw MT, Brown LD, Huang K (2013) Do sell-side analysts exhibit differential target price forecasting ability? Rev Acc Stud 18(4):930-955

Brav A, Lehavy R (2003) An empirical analysis of analysts' target prices: short-term informativeness and long-term dynamics. J Financ 58(5):1933-1967

Brown LD, Call AC, Clement MB, Sharp NY (2015) Inside the "Black Box" of sell-side financial analysts. J Account Res 53(1):1-47

Cascino S, Clatworthy M, Osma BG, Gassen J, Imam S, Jeanjean T (2014) Who uses financial reports and for what purpose? Evidence from capital providers. Account Eur 11(2):185-209

Chlomou G, Demirakos E (2020) How do financial analysts implement the sum-of the-parts (SOTP) valuation framework? Int Rev Financ Anal 70:1-12 
Christensen HB, Hail L, Leuz C (2013) Mandatory IFRS reporting and changes in enforcement. J Account Econ 56(2-3):147-177

Damodaran A (2012) Investment valuation. Tools and techniques for determining the value of any asset, 3rd edn. Wiley, Hoboken

Dechow PM, You H (2019) Understanding the determinants of analyst target price forecasts. Working Paper, available at: https://papers.ssrn.com/sol3/papers.cfm?abstract_id=2412813

Demerens F, Delvaille P, Manh AL, Parè J-L (2017) The use of segment information by financial analysts and forecast accuracy: a study on European intermediate-size companies. Thunderbird Int Bus Rev 59(5):595-612

Demirakos EG, Strong NC, Walker M (2004) What valuation models do analysts use? Account Horiz 18(4):221-240

Demirakos EG, Strong NC, Walker M (2010) Does valuation model choice affect target price accuracy? Eur Account Rev 19(1):35-72

Fama EF, French KR (2019) Industry classification. Available online at http://mba.tuck.dartmouth.edu/ pages/faculty/ken.french/data_library.html

Gleason CA, Johnson WB, Li H (2013) Valuation model use and the price target performance of sell-side equity analyst. Contemp Account Res 30(1):80-115

Green J, Hand JRM, Zhang XF (2016) Errors and questionable judgements in analysts' DCF models. Rev Acc Stud 21(2):596-632

Groysberg B, Healy P, Chapman C (2008) Buy-side vs sell-side analysts' earnings forecasts. Financ Analysts J 64(4):25-39

Grüber S (2015) Intangible values in financial accounting and reporting-an analysis from the perspective of financial analysts. Dissertation, Springer, Wiesbaden.

Healy PM, Palepu KG (2001) Information asymmetry, corporate disclosure, and the capital markets: a review if the empirical disclosure literature. J Account Econ 31(1-3):405-440

Hope OK (2003) Disclosure practices, enforcement of accounting standards, and analysts' forecast accuracy: an international study. J Account Res 41(2):235-272

Imam S, Barker R, Clubb C (2008) The use of valuation models by UK investment analysts. Eur Account Rev 17(3):503-535

Imam S, Chan J, Shah SZA (2013) Equity valuation models and target price accuracy in Europe. Int Rev Financ Anal 28(1):9-19

Kaustia M, Laukkanen H, Puttonen V (2009) Should good stocks have high prices or high returns? Financ Anal J 65(3):55-62

Kelly K, Low B, Tan H-T, Tan S-K (2012) Investors' reliance on analysts' stock recommendations and mitigating mechanisms for potential overreliance. Contemp Account Res 29(3):991-1012

Kerl AG (2011) Target price accuracy. Bus Res 4(1):74-96

Koller T, Goedhart M, Wessels D (2015) Valuation-measuring and managing the value of companies, 6th edn. Wiley, Hoboken

Kothari SP (2001) Capital markets research in accounting. J Account Econ 31(1-3):105-231

Lang MH, Lundholm RJ (1993) Cross-sectional determinants of analyst ratings of corporate disclosures. J Account Res 31(2):246-271

Lang MH, Lundholm RJ (1996) Corporate disclosure policy and analyst behavior. Account Rev 71(4):467-492

Lys T, Soo LG (1995) Analysts' Forecast Precision as a Response to Competition. J Account Audit Financ 10(4):751-765

Oberdörster T (2009) Finanzberichterstattung und prognosefehler von finanzanalysten (English translation: Financial reporting and financial analysts ' forecast error). Dissertation, Gabler, Wiesbaden

Paarz R (2011) Einfluss der Rechnungslegung auf Finanzanalysten: Eine empirische Analyse von Prognosegenauigkeit und Bewertungsverfahren von Finanzanalysten in Deutschland (English translation: The Effect of Financial Reporting on Financial Analysts: An Empirical Analyses of Financial Analysts“ Forecast Accuracy and the used Valuation Methods in Germany). Dissertation, Lang, Peter, $\mathrm{GmbH}$, Internationaler Verlag der Wissenschaften, Frankfurt/Main

Ramnath S, Rock S, Shane P (2008) The financial analyst forecasting literature: a taxonomy with suggestions for further research. Int J Forecast 24(1):34-75

Schipper K (1991) Commentary on analysts' forecasts. Account Horiz 5(4):105-121

Sengupta P (1998) Corporate disclosure quality and the cost of debt. Account Rev 73(4):459-474 
Wehrfritz M (2012) Nationale Prägung der IFRS-Anwendung-empirische Erkenntnisse für Deutschland und Großbritannien (English translation: National characteristics of IFRS application-empirical Analyses for Germany and United Kingdom). BoD-Books on Demand, Köln

You S (2014) Valuation-driven profit transfer among corporate segments. Rev Acc Stud 19(2):805-838

Publisher's Note Springer Nature remains neutral with regard to jurisdictional claims in published maps and institutional affiliations.

\section{Authors and Affiliations}

\section{Gülcan Erkilet ${ }^{1} \cdot$ Gerrit Janke $^{2} \cdot$ Rainer Kasperzak $^{1}$}

Gülcan Erkilet

guelcan.erkilet@uni-due.de

Gerrit Janke

gerrit.janke@credit-suisse.com

1 Chair of International Accounting, University of Duisburg-Essen, Universitätsstraße 2, 45141 Essen, Germany

2 Investment Banking and Capital Markets, Credit Suisse AG, Taunustor 1, 60310 Frankfurt, Germany 